\title{
Real-Time Container Storage Location Assignment at a Seaport Container Transshipment Terminal: Dispersion Levels, Math Programming Strategies, and Sensitivity Analyses
}

\author{
Matthew E. H. Petering ${ }^{a^{*}}$ \\ Yong $\mathrm{Wu}^{\mathrm{b}}$ \\ Wenkai $\mathrm{Li}^{\mathrm{c}}$ \\ Mark Goh ${ }^{\mathrm{de}}$ \\ Robert de Souza ${ }^{\mathrm{e}}$ \\ Katta G. Murty ${ }^{\mathrm{f}}$
}

${ }^{\text {a }}$ Department of Industrial \& Manufacturing Engineering, University of Wisconsin-Milwaukee, Milwaukee, WI 53201, USA

* Corresponding author. Tel.: +1 414229 3448; fax: +1 414229 6958. Email address: mattpete@uwm.edu (M. Petering).

${ }^{\mathrm{b}}$ Dept. of International Business and Asian Studies, Griffith University, Gold Coast, Australia

${ }^{c}$ Graduate School of International Management, International Univ. of Japan, Niigata, Japan

${ }^{d}$ NUS Business School, National University of Singapore, 1 Business Link, Singapore 117592

e The Logistics Institute-Asia Pacific, 21 Heng Mui Keng Terrace, \#04-01, Singapore 119613

${ }^{\mathrm{f}}$ Department of Industrial and Operations Engineering, University of Michigan, Ann Arbor, MI 48109-2117, USA

\begin{abstract}
We present the results of four experiments that link a seaport container terminal's overall productivity to the system that automatically selects storage locations for export containers in real time as they enter the terminal. Experiment 1 introduces the concept of a container dispersion level and tests the performance of several dispersion levels at various terminals. Experiment 2 considers the math-programming-based yard template concept that has received much attention in recent years. By evaluating yard templates under simulated operating conditions, we provide a link between yard templates and overall terminal productivity that has been absent from previous studies. Experiments 3 and 4 examine how the vessel berthing policy and yard truck traveling speed affect the performance of the storage systems considered in Experiments 1-2. The experiments provide insight into options for real-time decision making at container terminals that is rare in that (1) performance is measured in overall terms and (2) detailed measures of performance for all entities - berths, vessels, groundslots, quay cranes, yard cranes, yard trucks, and containers - involved in every container's complete lifetime at the terminal are provided.
\end{abstract}

\section{Keywords}

Seaport container terminal; Container storage location assignment; Real-time decision making; Online algorithms; Simulation; Math programming; Gross crane rate 


\section{Introduction}

As world population grows and economies develop, it is becoming increasingly important to improve the productivity of seaport container terminals - the port facilities where container vessels are loaded and unloaded and where 20', 40', and 45' long steel containers are temporarily stored while awaiting a future journey. Container terminal operations - the fundamentals of which are described by Günther and Kim (2006), Murty et al. (2005a, 2005b), and Monaco et al. (2009) - are the focus of much recent academic research. See the survey articles by Carlo et al. (2014a, 2014b, 2015), Stahlbock and Voß (2008), and Steenken et al. (2004) for more details.

In this paper, we consider the real-time management of a land-scarce, pure transshipment container terminal in which containers are stacked high, equipment is manually controlled by human operators, and all containers arrive and depart by vessel. Figure 1 shows the general layout of such a terminal. QCs (quay cranes) unload and load container vessels. They transfer cargo between vessels and YTs (yard trucks). YTs transport cargo between the shore and a storage yard (yard). YCs (yard cranes, RTGs, rubber-tired gantry cranes) transfer containers between YTs and stacks in the yard. The terms zone, column, block, row, 40' yard bay, slot, 40' stack, and groundslot refer to various portions of the yard (Figure 1).

We assume all containers are 20' or 40' long and all QCs handle one container at a time. We also assume that the terminal operates according to a weekly schedule in which a fixed set of liner services visit the terminal at regularly scheduled times each week. The vessels belonging to a liner service are assigned to the same home berth and follow the same cyclical route (i.e. port sequence) with schedules that are staggered by one week. We further assume that the liner service onto which a container is loaded is always known when the container enters the terminal and does not change afterwards. We use GCR (gross crane rate, QC rate) as the measure of terminal performance to maximize over the long run. GCR equals the average number of QC lifts made per QC working hour. More information about the environment considered in this paper is available in Sections 1 and 2 of Petering (2015).

This study considers the problem of selecting storage locations for export containers in real time as they enter the terminal. Our study is rare in that (1) performance is measured in overall terms and (2) detailed measures of performance for all entities - berths, vessels, quay cranes, yard cranes, yard trucks, groundslots, and containers - involved in every container's complete lifetime at the terminal are provided.

To our knowledge, there are only six published studies that focus on, and present numerical results regarding, real-time container storage location assignment: Saanen and Dekker (2006a, 2006b), Dekker et al. (2006), Borgman et al. (2010), van Asperen et al. (2013), and Petering (2015). The first two papers lack aspect 2 from the previous paragraph; they are brief articles that appear in industry journals. The next three studies lack aspect 1 , and they consider terminals where the YC-YT handoff points are at the ends of the storage blocks. On the other hand, the study by Petering (2015) has aspects 1 and 2, and it assumes that the YC-YT handoff points are beside the storage blocks.

This paper continues the work begun by Petering (2015). Petering (2015) (i) describes the real-time container storage location assignment problem; (ii) proposes a generic algorithm for making real-time container storage decisions; and (iii) presents the results from a large simulation experiment. This study shares the main goal of Petering (2015) which is to identify settings for the proposed algorithm that maximize GCR at one or more container terminals. 
Table 1 shows four intermediate objectives that a container storage system could pursue in an effort to maximize GCR (Petering, 2015). Objectives A and B relate to minimizing container travel distances; objectives $\mathrm{C}$ and $\mathrm{D}$ relate to minimizing congestion. Note that objectives B and D relate to the future state of the terminal long after the real-time storage decision for an arriving container is made and the container is placed in the yard.

Table 2 shows the logic in the generic real-time container storage algorithm developed by Petering (2015). This algorithm is executed every time a QC places a container onto the trailer of a YT; it has negligible runtime and decides where the unloaded container will be stored in the yard. Whereas Petering (2015) evaluates various options for performing step 6 of this algorithm, this study focuses on the dispersion levels and yard templates that are the basis of steps 4 and 5 .

To facilitate reader understanding, we now review the workings of the real-time container storage algorithm (Table 2). Step 0 enforces a sort-and-store policy (Section 2.2 of Petering, 2015). In this step, the arriving container is, whenever possible, assigned to a partially-full stack of containers that share the arriving container's length, height, weight class, liner service onto which the container is loaded, and destination port. If such a partially-full stack exists, it is unique and the container is assigned to that stack; otherwise the container will be assigned to an empty stack and the procedure continues to step 1. In step 1, the algorithm determines if the storage decision will be postponed. A postponement happens if parameter simult $20=$ Yes and if the arriving container is the first of two 20' containers consecutively unloaded by the same QC onto the same YT. See Sections 4.2.2 and 5.3 of Petering (2015) for full details regarding simult20. The procedure terminates (continues to step 2) if the container storage decision is (is not) postponed. In steps 2 and 3, a list of empty yard stacks (i.e. candidate stacks) that can accommodate a container of the given length - 20' or 40'-is created. The conservation of empty 40 ' stacks for future 40' containers is considered when forming this list.

In step 4 (5), all stacks that do not agree with the container dispersion level (yard template) are deleted from the list of candidate stacks. These concepts are the focus of Sections 2 and 3 of this study. In steps 6-7, the remaining candidate stacks are evaluated using a penalty scheme as follows. First, a penalty score is computed for each storage block in the yard. This score is a (usually positive) real number representing the degree of undesirability for storing the container in the block. It is a weighted sum of ten penalty components numbered 1 to 10 , where the penalty weights are user-defined parameters (Tables 2 and 4 in Petering, 2015). A positive weight for penalty component (1-2, 3-4, 5, 6-9, 10) indicates that the system is pursuing objective (A, B, A\&B, C, D) respectively (Table 1). A penalty regime is a specific set of penalty weights. Each candidate stack receives the penalty score of the block in which it resides. The candidate stack with the lowest penalty score is selected as the container's storage location. Ties are broken randomly. See Section 5 of Petering (2015) for full details. The results from Petering (2015) indicate that GCR is 1-7\% higher when containers are stored according to a carefully selected penalty regime instead of being stored randomly.

This study presents the results of four experiments that test ideas for container storage location assignment that were not explored by Petering (2015). Experiment 1 rigorously introduces the concept of a container dispersion level and tests the performance of several dispersion levels at various terminals. Experiment 2 considers the math-programming-based yard template concept that has received much attention in recent years. Unlike previous contributions, this study evaluates yard templates under simulated operating conditions, providing a link between yard templates and overall terminal productivity that has been absent from previous studies. Experiments 3 and 4 examine how the vessel berthing policy and YT 
traveling speed affect the performance of the storage systems considered in Experiments 1-2. All experiments are conducted using a discrete event simulation model that is designed to reproduce the microscopic, stochastic, limited-information, real-time environment at a busy, land scarce, RTG-based, multiple-berth, pure transshipment terminal. Section 7 of Petering (2015) describes our general experimental setup. More details on the simulation model are available in Petering and Murty (2009), Petering et al. (2009), and Petering (2009, 2010, 2011, 2015).

This paper is organized as follows. Each experiment has its own self-contained section that includes a problem description, literature review, and discussion of the experimental setup and results. Sections 2, 3, 4, and 5 present our work on Experiments 1, 2, 3, and 4 respectively. Concluding remarks are made in Section 6.

\section{Experiment 1: Dispersion levels}

In this experiment, we perform a detailed investigation of the dispersion level concept that was briefly introduced by Petering (2015). Dispersion levels are incorporated into step 4 of the real-time container storage algorithm (Table 2). This experiment is the first evaluation of the dispersion level concept to appear in the literature.

\subsection{Dispersion levels defined}

The dispersion level specifies the level of dispersion in the yard for containers that are loaded at the same berth (Section 4.2.5 of Petering, 2015). More precisely, the dispersion level is a non-negative integer that defines a preferred storage territory (i.e. PST) for each berth, i.e. an area in the yard where the containers that are expected to be loaded at that berth should be stored. A dispersion level of $x$ means that the storage location assigned to a newly arriving container should be no more than $x$ columns away from the home berth of the liner service onto which it is loaded. Overall, a (low/high) dispersion level means that containers loaded onto the same liner service are stored in (concentrated/dispersed) fashion (very near to that liner service's home berth/throughout the entire yard).

Figures 2-3 illustrate the two terminal settings considered in this paper and various dispersion levels for each setting. In Setting 1 (2), the yard has 5 (10) zones and there are two columns (is one column) of yard blocks for each berth. A PST consists of the yard blocks that occupy the intersection of all yard zones with one or more yard columns. The top portion of Figure 2 shows how the PST for containers loaded onto liner services calling at berth 1 depends on the dispersion level. The PST for containers loaded onto liner services that call at berth 2 is the mirror image of what is shown. The top portion of Figure 3 shows the PST for containers loaded onto liner services that call at berth 5 for different dispersion levels; information for containers loaded onto other liner services is not shown. Note in Figures 2-3 that a dispersion level of $x$ in Setting 1 (2) means that containers should be stored only in the $2+2 x$ columns $(1+$ $2 x$ columns) centered about the home berth of the liner service onto which they are loaded. Any such columns that lie outside the terminal boundary are truncated and disregarded. Overall, $2 b-2$ $(b-1)$ is the highest dispersion level that is still meaningful for a terminal with $b$ berths in Setting 1 (2). At this maximum dispersion level, the entire yard is PST for all arriving containers. This is equivalent to having no PSTs at all. From the perspective of the berths, note that the PSTs for the berths are non-overlapping when the dispersion level is 0 and are overlapping to some degree 
for every dispersion level greater than 0. At the maximum dispersion level, the PSTs for all berths coincide with the entire terminal.

Overall, a low dispersion level emphasizes objective B whereas a high dispersion level emphasizes objective $\mathrm{D}$ (Table 1). Thus, the dispersion level can be used to evaluate the relative importance of objectives B and D.

Note that the preferences expressed in a dispersion level supersede those of the penalty scheme investigated by Petering (2015). Indeed, the dispersion level helps to decide which storage locations are eligible to receive an arriving container (Table 2, step 4), and the penalty scheme makes the final storage decision among the eligible locations (Table 2, steps 6-7).

\subsection{Experimental design and results}

The main goal of this experiment is to study the impact of the container dispersion level on the GCR at several container terminals. Our experiments here consider terminals of 2, 4, 6, 8, and 10 berths in each of the two settings described above. Detailed specifications for each setting are provided in Table 6 in Petering (2015). Two equipment fleet sizes-less equipment and more equipment - are considered, yielding $5 \times 2 \times 2=20$ different terminals. One such terminal is not considered owing to prohibitively long operational delays and simulation runtimes. Thus, 19 different terminals are considered. In this experiment, yard templates (Table 2, step 5) are not used, and parameter simult20 = Yes (Table 2, step 1).

Figures 4-5 display the scenarios considered and the experimental results for Settings 1-2 respectively. Results for each terminal are displayed in a separate graph. Each graph shows how GCR (y-axis) depends on the dispersion level (x-axis). Note that, in Setting 1, we test the even dispersion levels from 0 to $2 b-2$ ( $b$ is the number of berths) at all terminals and the odd dispersion levels at the 2- and 4-berth terminals. In Setting 2, we consider all dispersion levels from 0 to $b-1$ at all terminals.

Each dispersion level in each terminal is tested in four ways as shown in the bottom right of Figures 4-5. These four scenarios comprise two possible penalty regimes (Table 2, step 6) and two possible $Y C$ deployment systems. The " $\mathrm{C}+\mathrm{D}$ " penalty regime assigns weights 5 and 1 to penalty components 6 and 10 respectively and weight 0 to all other components; this penalty regime pursues objectives $\mathrm{C}$ and $\mathrm{D}$ (Table 1). The "no penalty" regime assigns weight 0 to all penalty components; it selects a random storage location among the candidate stacks. Two YC deployment systems - restrictive and free - are considered to remove experimental bias. The restrictive (free) YC deployment system restricts (does not restrict) the ability of YCs to freely congregate in small portions of the yard (Petering and Murty, 2009). We expect a high (low) container dispersion level to perform best when combined with a restrictive (free) YC deployment system.

Regarding equipment fleet sizes, there are 4 QCs, 10 YCs, and 20 YTs per berth in the less equipment scenarios. In the more equipment scenarios, there are 4 QCs and 36 YTs per berth, and there is a grand total of 25, 50, 70, 100, $120(30,50,70,100,120)$ YCs for the 2-, 4-, 6-, 8-, and 10-berth terminals in Setting 1 (2). YCs are evenly distributed among all zones at all times in all scenarios, and inter-zone cross gantry moves are forbidden in all scenarios to eliminate another source of bias.

Each data point in Figures 4-5 represents the average GCR from six independent simulation replications. For the scenarios using the "C+D" penalty regime, these replications are preceded by a single calibration replication that normalizes the penalties on a $0-1$ scale (Section 
5.2 of Petering, 2015). Thus, a total of 3068 simulation runs were performed to produce Figures 4-5. The CPU time per run ranged from $10 \mathrm{sec}$ to $56 \mathrm{~min}$. The highest GCR values at the 2berth terminals in Setting 1 and the 6-berth terminals in Setting 2 are displayed in the upper-right corner of the respective graphs. These GCR values come from the $\mathrm{C}+\mathrm{D}$ penalty regime, restrictive $\mathrm{YC}$ deployment system, and maximum container dispersion level.

Table 3 shows detailed results for the 8-berth terminal in Setting 1 with less equipment, penalty regime $\mathrm{C}+\mathrm{D}$, and the restrictive $\mathrm{YC}$ deployment system. Each row in the table maps to one data point in Figure 4. Twenty performance measures are displayed for each dispersion level that was tested. A key to these measures is provided beneath Table 3. The highest GCR value in the table is highlighted. The trends in this table are representative of the trends in many other scenarios. The GCR difference between dispersion level 4 and level 2 (6) is statistically significant at the $90 \%$ confidence level (is not statistically significant). The GCR difference between dispersion level 4 and the other levels is statistically significant at the $99 \%$ level.

\subsection{Discussion}

Figures 4-5 yield several managerial insights. In many cases, the best performing dispersion level is an intermediate value - neither very high nor very low. In these cases, the excessively high congestion (container travel distance) associated with a very low (high) container dispersion level appears to be harming productivity. These observations point to a likely trade-off between objectives B and D (Table 1) that we verify later on.

Note that the restrictive YC deployment system outperforms the free YC deployment system for most dispersion levels at most of the 19 terminals. Indeed, the restrictive system is superior to the free system for dispersion levels 2 and above at all terminals and for dispersion level 1 at more than half of the terminals. The free system is superior to the restrictive system only for dispersion level 0 at half of the terminals and for dispersion level 1 at a few terminals. These results agree with our intuition that the performance of the restrictive YC deployment system relative to the free system should improve as the dispersion level increases. To our knowledge, this is the first quantitative demonstration of a synergy between real-time YC deployment and real-time container storage systems in the literature. The poor performance of the free YC deployment system agrees with the results in Petering and Murty (2009). The remaining discussion therefore focuses only on the restrictive $\mathrm{YC}$ deployment system.

Figures $4-5$ also show that the $\mathrm{C}+\mathrm{D}$ penalty regime outperforms the no penalty regime. The difference in GCR is non-trivial-roughly $1.5 \mathrm{QC}$ lifts/hr (5\%) for the 4-, 6-, 8-, and 10berth terminals with less equipment in Setting 2, and about 1 (0.5) QC lifts/hr for the other scenarios with less (more) equipment. These results agree with Petering (2015) and show that overall GCR may increase by up to $5 \%$ if container storage locations are intelligently selected based on the real-time yard status when containers are discharged instead of being selected randomly. Given these results, the following discussion focuses only on the $\mathrm{C}+\mathrm{D}$ penalty regime.

We now consider the dispersion level itself, focusing only on the results for the restrictive YC deployment system and $\mathrm{C}+\mathrm{D}$ penalty regime shown in the dark curve at the top of the graphs in Figures 4-5. In these figures, note that GCR usually increases as the dispersion level is increased from level 0 to level 5. However, GCR usually decreases as the dispersion level is increased beyond level 5. Thus, a dispersion level of about 5 yields the best performance in most cases. This corresponds to containers being dispersed in the yard up to $2 \mathrm{~km}$ away from the vessels they are loaded onto, but no further (Figure 3). For most of the world's small- and 
medium-sized container terminals, this is equivalent to maximal dispersion of containers throughout the yard. This "maximum dispersion" recommendation for small- and medium-sized terminals performs very well under the current assumptions that (a) vessels always dock at their home berths and (b) the liner service onto which a container is loaded is always known when a container enters the terminal and does not change. If either of these assumptions is relaxed, this recommendation becomes even more compelling.

Table 3 provides detailed information to verify the trade-off between objectives B and D (Table 1). This trade-off is illustrated by the decreasing values in the "YT WaitYR" column and the increasing values in the "YT TravQL" column. As expected, these columns show that YTs spend (1) less time waiting in the yard for YCs to retrieve containers but (2) more time transporting containers from the yard to the quay as the dispersion level increases. In other words, the retrieval/loading process is characterized by lower yard congestion (objective D) but greater container travel distance (objective B) as the dispersion level increases. The superior performance of higher dispersion levels at small- and medium-sized terminals means that it is more beneficial to pursue objective $\mathrm{D}$ than objective $\mathrm{B}$ at these terminals.

Columns "YT WaitYR" and "YT WaitYS" in Table 3 show that YTs spend more time waiting for $\mathrm{YC}$ service in the yard as the dispersion level decreases no matter if they wish to retrieve or store containers. This trend is explained as follows. When the dispersion level is low (high), the container retrieval process that supports the loading of a particular vessel is concentrated (dispersed) in the yard. On the other hand, the container storage process associated with the unloading of a particular vessel is always dispersed throughout the yard, regardless of the dispersion level, because each unloaded container is equally likely to be transshipped to any other liner service calling at the terminal (Section 7.2 of Petering, 2015). The implications of the above statements at a busy, multiple-berth terminal are as follows. For a high dispersion level, the workload in the yard is more-or-less equally distributed among all columns at all times. For a low dispersion level, however, the workload is spread evenly throughout the yard at a given time only if all vessels are loading or all vessels are unloading. If there is a mix of loading and unloading vessels at a given time (which is usually the case), some columns will experience significantly more workload than others. Indeed, some columns will experience both loading and unloading activities, while others will only experience unloading activities. This workload imbalance increases the average YT time spent waiting for both types of YC service-retrieval and storage service - in the yard. To our knowledge, the "YT WaitYR" and "YT WaitYS" columns are the first results in the literature to quantitatively show how the yard congestion related to one vessel's loading operation negatively affects other vessels' unloading operations.

Table 3 contains other interesting trends. The "Cont WaitS" and "Cont TravQ" columns show the same trends as the "YT WaitYS" and "YT TravQL" columns but from the containers" perspective. Also, the "YT TravYR" column shows that YTs spend less time traveling to the yard to retrieve containers as the dispersion level decreases. This trend is explainable if we consider a YT that has just transferred a container to a QC during the loading of a particular vessel. If the dispersion level is high, there is no guarantee that another job exists whose pick-up location is in the column(s) nearest to the vessel. However, if the dispersion level is low, there might be as many as four jobs (one per QC loading the vessel) whose pick-up locations are in the yard column(s) nearest to the vessel. Thus, the likelihood that the YT's next job involves a short journey to the yard to retrieve another container increases as the dispersion level decreases.

Table 3 also provides insight into container terminal operations in general. Note that the numbers in the "QC WaitL" column are larger than those in the "QC WaitU" column for all 
scenarios. This indicates that most QC delays occur during loading, not unloading. This is not surprising given the fact that YTs bringing containers to the quay during loading are typically not substitutable, whereas YTs bringing empty trailers to the quay during unloading are substitutable. Also, note the high negative correlation between GCR and the terms in the "QC Wait" column. In particular, GCR is the highest (at 27.61 QC lifts/hr) precisely when the fraction of total QC time spent waiting for YTs is the lowest (.262). There is also a high negative correlation between GCR and the terms in the "YT Total" column. Finally, note the positive correlation between GCR and the berth-on-arrival rate (BOA Rate), YC productivity (YC Prod), and YT productivity (YT Prod). These phenomena are hardly surprising.

\section{Experiment 2: Math programming strategies}

We now explore the math-programming-based yard template concept that has received much attention in the recent literature. Studies considering yard templates and related concepts have been conducted by Bruzzone and Signorile (1998), Chen et al. (2004), Lee et al. (2006), Lim and Xu (2006), Fu et al. (2007), Cordeau et al. (2007), Han et al. (2008), Ku et al. (2010, 2012), Zhen et al. (2011, 2016), Jiang et al. (2012, 2013, 2014), Zhen (2013, 2014, 2016), Jin et al. (2015), and Tao and Lee (2015).

A yard template expresses a managerial storage preference (Section 4.2.4 of Petering, 2015 ) in that it pre-assigns to each liner service certain preferred storage locations (PSLs) in the yard where cargo loaded onto the liner service should be stored (Zhen et al., 2011). A yard template is created offline by solving a math programming problem. It remains unchanged as long as the terminal's weekly schedule, its weekly berth plan, and the expected cargo volume loaded onto each liner service are unchanged. The creation of a yard template is a tactical decision that affects real-time container storage decisions (Table 2, step 5) like a dispersion level.

Despite the popularity of the yard template concept in the literature, to our knowledge there are no published studies that test its performance under simulated operating conditions. In addition, there are no studies that compare the performance of different types of yard templates at the same terminal. The purpose of this experiment is to fill this gap in the literature.

\section{1. $\quad$ Yard templates defined}

A yard template can be used to pursue objectives B and/or D in Table 1. It can work towards objective B by putting a liner service's PSLs close to the liner service's home berth. It can work towards objective D by spreading, throughout the yard, the PSLs for the liner services that are expected to be present at the same time.

A yard template is visually displayed on a yard map by coloring each groundslot according to the liner service(s) that containers in the groundslot are loaded onto. For example, consider the terminal depicted in Figure 6. The weekly schedule at the top of Figure 6 indicates that six vessels (i.e. liner services) call at this terminal each week. Vessel 1 is expected to arrive Sunday morning and depart Tuesday morning and has home berth 1 ; vessel 2 is expected to arrive Sunday afternoon and depart Tuesday at noon and has home berth 2; and so on. Note that each vessel has a different color. The yard map in the middle of Figure 6 illustrates one possible yard template for this terminal. Here, the PSLs for the cargo loaded onto vessel 1 are blocks 5 and 7; all other cargo has an equally low priority for being stored in these blocks. The PSLs for the cargo loaded onto vessel 2 are blocks 1 and 8, and so on. Note that the PSLs for each liner 
service form two large regions, each the size of an entire block. Such a template might give rise to a lot of yard congestion when vessels are loading. In addition, this template creates long container travel distances from yard to quay during loading.

The yard template at the bottom of Figure 6 is probably better for this terminal. In this template, each liner service's PSLs consist of 16 non-adjacent small regions-each the size of a 40' yard bay. This template also puts containers close to the expected berthing locations of the vessels they are loaded onto. For example, all cargo loaded onto vessels 1, 3, or 5 is stored on the left side of the yard, close to berth 1 . This template embodies objectives B and D to a greater degree than the template above it.

\section{2. $\quad$ Constructing yard templates}

We now present a general method for automatically creating a variety of yard templates. The first step is to look at the total yard capacity and the expected amount of cargo loaded onto each vessel (i.e. liner service) each week. This determines the quantity $M_{v}=$ the minimum number of groundslots needed to store the cargo loaded onto vessel $v$, for all $v$. The second step is to devise a yard partition. A yard partition is an exhaustive partitioning of the storage yard into disjoint regions. Each region consists of one or more contiguous 40' stacks. The maximum size of a region is an entire block; the minimum size is a $40^{\prime}$ stack. The partition may also specify if there is a home berth preference, i.e. if the PSLs for containers must be close to the home berths of the vessels onto which they are loaded. The final step is to assign one or more vessels (typically only one) to each region in the yard partition. The final output of this process is a yard template in which each vessel's PSLs are the regions to which the vessel is assigned.

Table 4 presents a math model for creating a yard template according to the above procedure. The value of parameter $T_{v, w}$ in Table 4 is computed based on the terminal's weekly schedule (Sect. 1). In the model, constraint (1) ensures that each yard region is regarded as a PSL for at least one liner service's loading cargo. Constraint (2) ensures that enough PSLs are allocated to each liner service calling at the terminal. Constraint (3) relates the two kinds of binary decision variables to each other. The objective is to minimize a combination of three things: (a) an estimate for the number of instances per week in which two containers simultaneously need to be retrieved from a small portion of the yard where only one YC may work at a time; (b) an estimate for the number of instances per week in which two containers simultaneously need to be retrieved from the same yard zone; and (c) an estimate for the total distance that containers travel each week from their storage locations to their loading vessels.

Parts (a) and (b) of the objective function pursue objective D, and part (c) pursues objective B (Table 1). The goal of (a) is to minimize retrieval clashing. A retrieval clash occurs when the job sequences of two or more QCs require the near-simultaneous retrieval of two or more containers from nearby yard locations. The goal of (b) is to spread the workload at any given time among different yard zones so that YCs do not have to make time-consuming, interzone, cross gantry moves to absorb the workload in other zones. The number of terms in subobjective (b) is much higher than (a), so $W_{1}$ should be very small. Sub-objectives (a) and (b) are quadratic as we are minimizing interaction cost. The quadratic objective function and millions of decision variables make it hard to find provably optimal solutions to this math program.

We developed a simulated annealing (SA) algorithm that quickly finds good solutions to the math program in Table 4 . The procedure starts with a high quality initial feasible solution (i.e. yard template) which is easily generated. During each iteration, a neighboring solution is 
generated by swapping the liner services assigned to several regions, and the principles of simulated annealing are used to determine whether or not the neighbor replaces the current solution. The best solution visited during 10,000 iterations is the final yard template that is used. In our experiments, a new yard template is generated at the start of each simulation run. Note that, owing to the randomness in the SA procedure, the same yard partition can give rise to hundreds of different yard templates.

\subsection{Experimental design and results}

We evaluate the above yard template concept at six container terminals. These are the same six terminals considered in Section 8 of Petering (2015): the 2-berth terminal in Setting 1 (Figure 2) with scarce, less, and more equipment and the 6-berth terminal in Setting 2 (Figure 3) with scarce, less, and more equipment. As in Petering (2015), there are a total of 15, 20, 25 (50, $60,70) \mathrm{YCs}$ in the scarce, less, and more equipment scenarios at the 2-berth (6-berth) terminal. There are 3,5, and 9 YTs per working QC in these three scenarios respectively. Dispersion levels (Section 2) are not used, and parameter simult $20=$ No (Table 2, step 1).

Table 5 shows the yard partitions used for constructing the yard templates in this experiment. In all cases, the yard is partitioned into equally sized regions, with each liner service being allocated an equal number of PSL regions that do not overlap with any other liner service. This table shows the region size for each partition and the number of PSL regions for each liner service at the 2-berth and 6-berth terminals respectively. The regions for all partitions except 5 and $5 \mathrm{H}$ consist of one or more contiguous 40' yard bays. A low (high) partition number corresponds to having few (many), large (small) regions - that is, concentrated (dispersed) storage of the containers loaded onto each liner service. An " $\mathrm{H}$ " following the partition number indicates that the PSLs for each liner service must be as close as possible to the liner service's home berth - that is, in the 1 (2) column(s) closest to the vessel's home berth in the case of the 6berth (2-berth) terminal. Partition 1, for example, has very large regions consisting of 21 contiguous 40' yard bays; this is the size of an entire (42-slot, 6-row) yard block in our experiments (Figures 2-3). Partition $4 \mathrm{H}$, on the other hand, has small regions consisting of one 40 ' yard bay, and all cargo is stored as close as possible to the home berth of the liner service onto which it is loaded. Partition $1(4 \mathrm{H})$ is depicted in the middle (at the bottom) of Figure 6.

In the SA algorithm that makes yard templates in this experiment, we set $W_{1}=0$ to save CPU time and $W_{2}=0$ (Table 4) because a strong home berth preference is already built into the "H" yard partitions.

The yard partitions in Table 5 are compared to a "no partition" option that does not use a yard partition or yard template. In this option, the PSLs for all liner services coincide with the entire yard. This is equivalent to having no PSLs at all.

Note that many published studies only consider yard partitions with sub-blocks (i.e. regions) that consist of four contiguous 40' yard bays. This corresponds to a partition number between 2 and 3 (Table 5). In this experiment, however, we consider yard partitions with different region sizes, and we also consider an option with no partition.

Preliminary experiments revealed a synergy between the container storage system and the system that deploys YCs among blocks in the same zone in real time. To remove the bias introduced by the YC deployment system, both the "restrictive" and "free" YC deployment systems are considered in all cases (Petering and Murty, 2009). 
Two penalty regimes - "no penalties" and " $\mathrm{C}$ " - are evaluated for each combination of terminal, yard partition, and YC deployment system. Thus, a total of $2 \times 6 \times 11 \times 2=264$ scenarios are considered. The "C" penalty regime assigns weight 1 to penalty component 8 and weight 0 to the other components. This regime pursues objective $\mathrm{C}$ which is complementary to the objectives pursued by a yard template-B and/or D.

Table 6 (7) shows the main experimental results for the 2-berth (6-berth) terminals. These tables show the average GCR achieved by the eleven yard partition options for every combination of six terminals, two YC deployment systems, and two penalty regimes. Each value in Table 6 (7) is the average GCR observed during ten (six) independent simulation replications. The results for the restrictive YC deployment system in the "None" column are copied from Petering (2015). The CPU time per replication ranged from $14 \mathrm{sec}$ to $25 \mathrm{~min}$. The lightly shaded values indicate the $\mathrm{YC}$ deployment system with better average performance for a given terminal and yard partition. The darkly shaded values indicate the highest GCR value at each terminal.

Figure 7 provides a graphical summary of the results in Tables 6-7. It shows the average performance of the eleven yard partitions at each terminal. Each data point in Figure 7 shows the average of two lightly shaded cells in Tables 6-7. Among the two YC deployment systemsrestrictive or free - only the result with a higher average GCR (across two penalty regimes) is shown. Dark (light) points correspond to the restrictive (free) YC deployment system.

Table 8 shows detailed results for the 6-berth terminal with less equipment and penalty regime $\mathrm{C}$ for both $\mathrm{YC}$ deployment systems. Each row in the table corresponds to a different GCR value inside a dashed rectangle in Table 7 . Twelve performance measures are displayed. A key to the measures not described in Table 3 is provided beneath the table. The highest GCR in the table is shaded. The difference between this GCR and the GCR for no partition and the restrictive YC deployment system is not statistically significant. The difference between this GCR and all other GCR values in the table is statistically significant at the $99 \%$ confidence level.

\subsection{Discussion}

We now sequentially discuss the performance of the (1) YC deployment systems, (2) container storage system, and (3) other terminal subsystems. Figure 7 and the corresponding shaded values in Tables 6-7 reveal a notable synergy between the YC deployment system and the yard partition. In particular, the free (restrictive) YC deployment system generally performs better with low (high) partition numbers and " $\mathrm{H}$ " ("non- $\mathrm{H}$ ") yard partitions. When no partition is used, the restrictive YC system generally outperforms the free system. These results agree with intuition. Indeed, lower-numbered and " $\mathrm{H}$ " yard partitions create workload imbalances in the yard when one or more vessels are loading. These imbalances are best handled by a free YC deployment system that allows several YCs to congregate in the same block at the same time, not a restrictive YC deployment system that forces YCs to spread out among all yard blocks at all times. These observations confirm the need for an integrated approach to container terminal research that considers interactions among different decision making systems.

According to Tables 6-7, the overall ranking of the four possible combinations of YC system (restrictive or free) and yard partition (high or low) from best to worst performance is as follows: restrictive-high, free-high, free-low, restrictive-low. Overall, the restrictive YC deployment system generally outperforms the free YC deployment system. Indeed, the darkly shaded values in Tables 6-7 indicate that the highest GCR value obtained at five of the six terminals occurs when the restrictive YC system is used. Note that the restrictive YC system's 
superiority over the free system is greater when (1) equipment is less plentiful and (2) the terminal is larger.

We now focus on the container storage system. According to Figure 7, the higher numbered yard partitions outperform the lower numbered partitions at all six container terminals. Indeed, GCR increases almost monotonically in the yard partition number when the type of partition - "H" or "non-H" - is held constant. The overall ranking of the yard partitions across all six terminals can be obtained by averaging the twelve shaded cells for each partition in Tables 6-7. According to these computations, the five best yard partitions (starting with the best) are "no partition", 5, 5H, 4, 4H with overall average GCR values of 30.21, 30.16, 29.86, 29.79, and 29.68 respectively. Interestingly, partitions $4 \mathrm{H}$ and $5 \mathrm{H}$ perform slightly worse on average than partitions 4 and 5 respectively. In other words, no advantage is gained by placing containers close to the home berth of the vessel onto which they are loaded. This finding agrees with Experiment 1 and Petering (2015) which found the pursuit of objective B (Table 1) to be counterproductive at small- and medium-sized terminals. Overall, it is better to store the cargo loaded onto each vessel in dispersed fashion than to concentrate it in the yard in large contiguous regions and/or in the columns closest to the home berth of the vessel onto which it is loaded.

Note the outstanding performance of the "no partition" option. Unlike its competitors, this simple option is not optimized; no math modeling or math programming is necessary to implement it. Yet, when tested under simulated operating conditions, this system achieves the highest overall average GCR among the eleven partition options.

According to Tables 6-7, the $\mathrm{C}$ penalty regime outperforms the no penalty regime in all cases. This result agrees with Experiment 1 and Petering (2015) and highlights the importance of objective $\mathrm{C}$-minimizing YT congestion in the vicinity of container storage locations when containers are being stored.

Table 8 shows that the yard partitions are working as intended. The "Cont TravQ" ("YT TravQL") column shows a large difference in container (laden YT) traveling time from yard to quay for the "non-H" versus " $\mathrm{H}$ " partitions. Thus, the " $\mathrm{H}$ " partitions are indeed storing containers closer to the home berths of the vessels onto which they are loaded. The values in the "YT WaitYS" column, however, show that the "H" partitions also create additional congestion and delays for the YTs involved in the retrieval/loading process.

The "YC Moves" column shows the number of inter-block linear gantry moves (Figure 1) made by the YCs. For the restrictive YC deployment system, such moves are forbidden because exactly one YC must be present in each block at all times (Section 7.2 of Petering, 2015). For the free YC deployment system, about 60,000 inter-block moves are made by all YCs during the two week data collection period. This equates to about 3 inter-block moves per hour per YC. This explains why the fraction of YC time spent linear gantrying as shown in the "YC Gantry" column is higher for the free system than the restrictive system.

Table 8 shows that low-numbered yard partitions are associated with major bottlenecks in the yard which become less serious as the partition number increases. Column "Cont WaitS" shows that the time an average container spends sitting on a YT waiting to be stored by a YC decreases dramatically as the partition number increases. Column "YT WaitYS" shows a similar trend from the perspective of the YTs. In addition, column "Cont WaitR" shows that the time an average container spends waiting for a $\mathrm{YC}$ to retrieve it after the request to retrieve it first appears in the terminal operating system (TOS) decreases substantially as the partition number increases. Furthermore, the "Avg \# YT-Y" and "Avg \# YT-Q" columns show that the timeaveraged ratio of YTs heading towards or waiting in the yard versus YTs heading towards or 
waiting at the quay decreases from 3-10 to a low of about 1.6 as the partition number increases. A high value for this ratio indicates a bottleneck in the yard which negatively impacts GCR. Overall, it would be wise to minimize yard bottlenecks by using higher partition numbers.

The yard bottlenecks associated with low partition numbers are a result of workload imbalances in the yard when one or more vessels are loading. In such cases, the retrieval traffic — created by YTs that wish to retrieve containers from the yard-is intense in some yard regions and absent in other regions. However, the storage traffic is always spread throughout the yard. This creates a major workload imbalance among the storage blocks. The YC fleet has difficulty coping with this imbalance because there are physical limits on the number of YCs that can simultaneously work in close proximity (Figure 2 in Petering, 2015). Whereas some YCs are overloaded with work, even more YCs sit idle. Indeed, column "YC Idle" shows that the time an average $\mathrm{YC}$ spends sitting idle increases as the partition number decreases.

We now summarize the results from this experiment. A math-programming-based yard template concept can be integrated into a real-time container storage location assignment system. The resulting system is viable. However, at the small- and medium-sized terminals considered, such a system performs no better than a system that does not use yard templates.

Note that several published studies - including those by Lee et al. (2006), Han et al. (2008), Zhen et al. (2011, 2016), Jiang et al. (2012, 2013), and Zhen (2013, 2014, 2016) attempt to minimize yard congestion via the offline construction of yard templates with $s u b$ blocks (i.e. regions) consisting of four contiguous 40' yard bays. This corresponds to a yard partition number between 2 and 3 (Table 5). However, the results obtained here-via the online reproduction of yard congestion and its consequences within a fully-integrated discrete event simulation model —indicate that, if a yard template must be used, it should be based on yard partition 4 or 5 .

Overall, the results from Experiments 1-2 and Petering (2015) significantly challenge the idea of using dedicated (i.e. template-based, reservation-based) storage systems at busy, RTGbased, manually-operated, small- and medium-sized terminals. In an analog world, dedicated storage systems were universally adopted because they offered reliability to managers whose top priority was to not lose cargo. However, with most container terminals already possessing computerized real-time container tracking capability, there is little evidence to support the continued use of dedicated storage systems. Instead, our results show that new storage systemsbased on the concepts of maximum container dispersion, penalty regimes that pursue objectives $\mathrm{C}$ and $\mathrm{D}$, and real-time decision making at the latest possible moment-should be used.

\section{Experiment 3: Impact of vessel berthing policy}

We now conduct a sensitivity analysis showing the impact of the vessel berthing policy on the performance of the three container storage concepts - penalty regimes, dispersion levels, and yard templates - that are examined in Petering (2015), Experiment 1, and Experiment 2. A vessel berthing policy provides guidelines for deciding when and where vessels dock at a container terminal; it is relevant to this study because we assume that vessel arrival times are stochastic (Section 7.2 of Petering, 2015). To our knowledge, this is the first experiment in the literature to quantitatively show the interplay between vessel berthing policies and container storage location assignment strategies and their joint impact on container terminal performance. 


\subsection{Two vessel berthing policies defined}

Experiments 1-2 and Petering (2015) assume that vessels always dock alongside their home berths. Under such a "HomeBerth" policy, there is a separate queue for each berth, and arriving vessels always join the end of the queue leading to their home berth, even if another berth is vacant. A berth that becomes vacant is immediately refilled only if the queue leading up to the berth is nonempty. In this section, we introduce a new berthing policy-a first-come-firstserved (FCFS) policy - in which there is a single vessel queue feeding all berths. The FCFS policy works as follows. If a vessel's home berth is available when it arrives, the vessel immediately begins to dock at its home berth. Otherwise, if another berth is available, the vessel immediately begins to dock at the berth closest to its home berth. If no berth is available, the vessel joins the end of the queue of vessels waiting for a berth. A berth that becomes vacant is immediately refilled by the vessel at the front of the queue (if the queue is nonempty). To summarize, in the (HomeBerth/FCFS) policy, vessels (always/do not always) dock at their home berths but they (do not always/always) dock in order of their arrival.

Aspects of the HomeBerth and FCFS policies often appear in service agreements negotiated between shipping lines and container terminals. In such agreements, the terminal agrees to unload and load one or more liner services at specific times each week for a several month period. These agreements often contain language specifying a preferred berthing location (i.e. home berth) or docking priority (e.g. FCFS) for the vessels belonging to a liner service.

Among the objectives listed in Table 1, only objective B - minimizing expected container travel distance from the yard to the quay during retrieval/loading - is directly affected if vessels do not dock at their home berths. Thus, we hypothesize that GCR is sensitive (insensitive) to the berthing policy when a storage system that pursues (does not pursue) objective B is used.

\subsection{Experimental setup, results, and discussion}

Table 9 shows how the HomeBerth and FCFS berthing policies affect the performance of the penalty-scheme-based container storage systems tested in trials 0-10 in Table 8 in Petering (2015). This table only includes results for the 6-berth terminal in Setting 2 with less equipment. Trial 0 tests the no penalty regime in which all penalty weights are zero; this storage system selects random storage locations. Trial $t$ tests the performance of the penalty regime which solely places weight on penalty component $t$ for all $t$ from 1 to 10 (Table 4 in Petering, 2015). The results for the (HomeBerth/FCFS) berthing policy are displayed in the (left/center) portion of the table and are (copied from Petering (2015)/new results in Experiment 3). For the HomeBerth (FCFS) policy, the average vessel docked 0 (1.76) berths away from its home berth. Each value in Table 9 is the average GCR from six independent simulation runs. Besides the berthing policy, the experimental setup is identical to Section 8.1 of Petering (2015).

Note in Table 9 that the GCR in trials 6-10 is higher than that in trials 1-5 for both berthing policies. Thus, GCR is higher when the container storage system minimizes congestion, by pursuing objective $\mathrm{C}$ or $\mathrm{D}$, instead of minimizing container travel distances by pursuing objective A or B. Note that the GCR difference between the two berthing policies is small (less than $0.30 \mathrm{QC}$ lifts/hr) in all cases except trials 3-4. In trials 3-4, the GCR under the FCFS policy is about $0.90 \mathrm{QC}$ lifts/hr less than under the HomeBerth policy. These results are reasonable. Indeed, among the ten penalty components, only components 3-5 pursue objective B (Table 4 in Petering, 2015). Furthermore, only components 3-4 consider horizontal container travel distance 
(in the east-west direction in Figure 1) during loading; component 5 considers vertical container travel distance which is not affected by vessel berthing locations at the terminals we consider. Also note in the last two columns of Table 9 that the vessel berthing policy significantly affects (1) the fraction of YT time spent hauling containers from the yard to the quay during loading and (2) the average container traveling time from yard to quay during loading in trials 3-4 only; the effect is negligible in the other trials. These results show that the vessel berthing policy only affects the performance of storage systems that pursue objective B through the minimization of horizontal container travel distance.

Figure 8 shows how the vessel berthing policy affects the performance of the dispersionlevel-based container storage systems introduced in Experiment 1. A low (high) dispersion level corresponds to the pursuit of objective B (D) at the expense of objective D (B). The results for the HomeBerth (FCFS) policy are displayed on the left (right) of Figure 8 and are copied from Experiment 1 (new results in Experiment 3). Except for the berthing policy, the experimental setup is identical to Experiment 1. The top (bottom) of Figure 8 shows results for the 8-berth (10-berth) terminal in Setting 1 (2) with less equipment. Each data point represents the average GCR from six simulation runs. At the 8-berth (10-berth) terminal, the average vessel docked 2.46 (3.14) berths away from its home berth under the FCFS berthing policy.

Figure 8 shows that the optimal dispersion level is much higher with the FCFS berthing policy than the HomeBerth policy. We explain this result as follows. Under the FCFS policy, vessels do not always dock at their home berths, so it is better to disperse the containers loaded onto each liner service throughout the yard to minimize congestion and be ready for loading at any berth. For the HomeBerth policy, each vessel is guaranteed to dock at its home berth, so containers should be placed somewhat closer to the home berths of the liner services onto which they are loaded. Also note that the GCR is lower under the FCFS policy than the HomeBerth policy for all dispersion levels except the maximum dispersion level. At the maximum dispersion level, the two policies perform equally well. This result agrees with our hypothesis that the GCR for the storage systems that (pursue/do not pursue) objective B-i.e. those (not using/using) the maximum dispersion level — is (sensitive/insensitive) to the berthing policy.

Table 10 shows how the vessel berthing policy affects the performance of the yardtemplate-based container storage systems tested in Experiment 2. This table only includes results for the 6-berth terminal in Setting 2 with less equipment. The results for the HomeBerth (FCFS) berthing policy are displayed in the left (center) portion of the table and are copied from Experiment 2 (new results in Experiment 3). For the HomeBerth (FCFS) policy, the average vessel docked 0 (1.86) berths away from its home berth. Each GCR value in Table 10 is the average GCR from six simulation runs. Except for the vessel berthing policy, the experimental setup is identical to Experiment 2. Notice in the last two columns of the table that the difference in (1) the fraction of YT time spent hauling containers from the yard to the quay during loading and (2) the average container traveling time from yard to quay during loading is negligible for all "non-H" yard templates but significant for all " $\mathrm{H}$ " yard templates. Regarding GCR, note that the GCR difference between the two berthing policies is small (less than 0.50 QC lifts/hr) for all "non-H" yard templates and large (more than 0.65 QC lifts/hr) for many of the " $\mathrm{H}$ " yard templates. This agrees with our previous observations that the berthing policy only affects the performance of container storage systems that pursue objective B.

Our conclusions from this experiment are as follows. The best performing container storage systems at small- and medium-sized terminals remain the same regardless of the vessel berthing policy. This is because (i) the best performing storage systems at these terminals pursue 
objectives $\mathrm{C}$ and/or $\mathrm{D}$ under either berthing policy whereas (ii) the berthing policy only affects the performance of storage systems that pursue objective B. At large terminals, however, the best performing storage system depends on the berthing policy because the best storage system pursues objective B to some extent (Figure 8 and Experiment 1). For such terminals, objective B should be pursued to a lesser extent under a FCFS berthing policy than a HomeBerth policy. Overall, GCR is at least as high under a HomeBerth berthing policy as a FCFS policy for every container storage system.

\section{Experiment 4: Impact of YT traveling speed}

We now investigate the impact of YT traveling speed on the performance of the container storage systems considered in Experiment 1 and Petering (2015). In Experiment 1 and Petering (2015), all YTs travel 40 (25) km/hr on average when empty (laden) and spend an average of 10 seconds making a turn. In this experiment, we reduce the YT speed by $50 \%$ so that YTs travel $20(12.5) \mathrm{km} / \mathrm{hr}$ on average when empty (laden) and spend an average of 20 seconds making a turn. To our knowledge, this is the first experiment in the literature to quantitatively show the interplay between truck traveling speed and container storage location assignment strategies and their joint impact on container terminal performance.

Figure 9 shows how YT traveling speed affects the performance of the dispersion-levelbased container storage systems introduced in Experiment 1. The results for YTs traveling at full (half) speed are displayed on the left (right) and are copied from Experiment 1 (new results in Experiment 4). This figure only shows results for the 6-berth terminal in Setting 2 with less equipment. Each data point represents the average GCR from six independent simulation runs. Except for YT traveling speed, the experimental setup is identical to Experiment 1.

Figure 9 contains two important results. First, the optimal dispersion level is much lower with YTs traveling at half speed $(=2)$ than at full speed $(=5)$. This result shows that objective B - minimizing average container travel distance from yard to quay during loading — becomes more relevant as YT traveling speed decreases. Second, slower YTs create a dampening effect. With faster YTs, the average GCR difference between the best and worst performing scenarios for a given dispersion level is $2.6 \mathrm{QC}$ lifts/hr - a 9\% difference. With slower YTs, the average GCR difference is $1.4 \mathrm{QC}$ lifts/hr-only a $6 \%$ difference. This result is intuitively plausible. Indeed, slower YTs place severe limitations on GCR, making the various options for the container storage and YC deployment systems less relevant.

Table 11 shows how YT traveling speed affects the performance of the penalty-schemebased container storage systems tested in trials 0-10 in Table 8 in Petering (2015). This table only includes results for the 6-berth terminal in Setting 2 with less equipment. The results for YTs traveling at (full/half) speed are displayed on the (left/right) and are (copied from Petering (2015)/new results in Experiment 4). Each GCR value in Table 11 is the average GCR from six simulation runs. Except for YT traveling speed, the experimental setup is identical to Petering (2015). For each combination of YT speed and penalty regime, we display the absolute GCR and GCR difference between the current trial and trial 0 .

Table 11 contains two important trends. First, the advantage of using penalty components 6-10 to pursue objectives $\mathrm{C}$ and $\mathrm{D}$ (trials 6-10) versus random storage (trial 0) decreases as the YT speed decreases. Second, the disadvantage of using penalty components 1-5 to pursue objectives A and B (trials 1-5) versus random storage also decreases as the YT speed decreases. Overall, having slower YTs tends to even out the performance of different penalty 
regimes, making them less important. This result agrees with our previous observation that slower YTs make the entire container storage system less relevant. Note, however, that the general impact of pursuing objectives A-D remains the same for both YT traveling speeds: pursuing objective $\mathrm{C}$ or $\mathrm{D}$ remains beneficial whereas pursuing objective $\mathrm{A}$ or $\mathrm{B}$ is usually detrimental. For the terminal at hand, objectives A-D can be ranked in the order C, D, A, B from most to least beneficial to overall terminal productivity. These results agree with Petering (2015).

\section{Conclusion}

This paper presents the results of four experiments that link a seaport container terminal's overall productivity to the system that automatically selects storage locations for export containers in real time as they enter the terminal. Scores of scenarios with different container storage systems, terminal sizes, yard layouts, equipment fleet sizes, yard crane deployment systems, vessel berthing policies, and truck speeds are considered. The results from 5969 threeweek-long simulation runs - comprising more than 1 billion simulated QC lifts - are presented.

The main results are as follows. First, the simulation model's short runtime shows that the proposed algorithm (Table 2) makes decisions quickly enough to keep pace with the realities of a dynamic, real-world container terminal operation. Second, Experiment 1 shows that containers loaded onto a given vessel should be stored in dispersed fashion up to $2 \mathrm{~km}$ away from the vessel's home berth. These findings challenge the ideas put forth by many researchers and practitioners who have focused on objective B - minimizing container travel distance from yard to quay during loading (Table 1). Third, Experiment 2 shows that math-programmingbased storage systems - which use yard templates to allocate to each liner service certain preferred storage locations where cargo loaded onto the liner service should be stored-perform no better than simple, rule-based systems that do not use math programming. These results challenge numerous published papers that present methods for constructing yard templates but do not demonstrate their benefit versus other concepts. Fourth, Experiments 3-4 show that containers loaded onto a given liner service should be dispersed (more/less) in the yard when vessels (are not/are) guaranteed to go to their home berths and/or when yard trucks travel more (quickly/slowly). Fifth, a slower truck traveling speed dampens the advantage or disadvantage of pursuing any given storage objective A-D (Table 1). Altogether, the experiments show that container storage objectives A-D can be ranked C, D, A, B from most to least beneficial at most of the terminals we consider. Thus, minimizing congestion is usually more important than minimizing container travel distance.

It is important to remember that the results of a simulation study should be interpreted with caution. Indeed, no simulation model can capture all complexities of a real container terminal operation. Nevertheless, we believe that this study provides rare insight into (1) the interplay between multiple real-time decision making systems and (2) the effect of microscopic container storage decisions on long-run, overall productivity at a container terminal.

\section{References}

Borgman, B., van Asperen, E., \& Dekker, R. (2010). Online rules for container stacking. OR Spectrum, 32, 687-716.

Bruzzone, A., \& Signorile, R. (1998). Simulation and genetic algorithms for ship planning and shipyard layout. Simulation, 71(2), 74-83. 
Carlo, H. J., Vis, I. F. A., \& Roodbergen, K. J. (2014a). Storage yard operations in container terminals: Literature overview, trends, and research directions. European Journal of Operational Research, 235(2), 412-430.

Carlo, H. J., Vis, I. F. A., \& Roodbergen, K. J. (2014b). Transport operations in container terminals: Literature overview, trends, research directions and classification scheme. European Journal of Operational Research, 236(1), 1-13.

Carlo, H. J., Vis, I. F. A., \& Roodbergen, K. J. (2015). Seaside operations in container terminals: Literature overview, trends, and research directions. Flexible Services and Manufacturing Journal, 27(2), 224-262.

Chen, P., Fu, Z., Lim, A., \& Rodrigues, B. (2004). Port yard storage optimization. IEEE Transactions on Automation Science and Engineering, 1, 26-37.

Cordeau, J. F., Gaudioso, M., Laporte, G., \& Moccia, L. (2007). The service allocation problem at the Gioia Tauro maritime terminal. European Journal of Operational Research, 176(2), 1167-1184.

Dekker, R., Voogd, P., \& van Asperen, E. (2006). Advanced methods for container stacking. OR Spectrum, 28(4), 563-586.

Fu, Z., Li, Y., Lim, A., \& Rodrigues, B. (2007). Port space allocation with a time dimension. The Journal of the Operational Research Society, 58, 797-807.

Günther, H. O., \& Kim, K. H. (2006). Container terminals and terminal operations. OR Spectrum, 28(4), 437-445.

Han, Y., Lee, L. H., Chew, E. P., \& Tan, K. C. (2008). A yard storage strategy for minimizing traffic congestion in a marine container transshipment hub. OR Spectrum, 30(4), 697-720.

Jiang, X., Chew, E. P., Lee, L. H., \& Tan, K. C. (2013). Flexible space-sharing strategy for storage yard management in a transshipment hub port. OR Spectrum, 35(2), 417-439.

Jiang, X., Chew, E. P., Lee, L. H., \& Tan, K. C. (2014). Short-term space allocation for storage yard management in a transshipment hub port. OR Spectrum, 36, 879-901.

Jiang, X., Lee, L. H., Chew, E. P., Han, Y., \& Tan, K. C. (2012). A container yard storage strategy for improving land utilization and operation efficiency in a transshipment hub port. European Journal of Operational Research, 22(1), 64-73.

Jin, J. G., Lee, D.-H., \& Hu, H. (2015). Tactical berth and yard template design at container transshipment terminals: a column generation based approach. Transportation Research Part E, 73, 168-184.

Ku, L. P., Chew, E. P., Lee L. H., \& Tan, K. C. (2012). A novel approach to yard planning under vessel arrival uncertainty. Flexible Services and Manufacturing Journal, 24, 274-293.

Ku, L. P., Lee L. H., Chew E. P., \& Tan, K. C. (2010). An optimization framework for yard planning in a container terminal: case with automated rail-mounted gantry cranes. $O R$ Spectrum, 32, 519-541.

Lee, L. H., Chew, E. P., Tan, K. C., \& Han, Y. (2006). An optimization model for storage yard management in transshipment hubs. OR Spectrum, 28(4), 539-561.

Lim, A., \& Xu, Z. (2006). A critical-shaking neighborhood search for the yard allocation problem. European Journal of Operational Research, 174(2), 1247-1259.

Monaco, M. F., Moccia, L., \& Sammarra, M. (2009). Operations research for the management of a transhipment container terminal: The Gioia Tauro case. Maritime Economics \& Logistics, 11(1), 7-35.

Murty, K. G., Liu, J., Wan, Y. W., \& Linn, R. (2005a). A decision support system for operations in a container terminal. Decision Support Systems, 39(3), 309-332. 
Murty, K. G., Wan, Y. W., Liu, J., Tseng, M. M., Leung, E., Lai, K. K., \& Chiu, H. W. C. (2005b). Hongkong International Terminals gains elastic capacity using a data-intensive decision-support system. Interfaces, 35(1), 61-75.

Petering, M. E. H. (2009). Effect of block width and storage yard layout on marine container terminal performance. Transportation Research Part E, 45(4), 591-610.

Petering, M. E. H. (2010). Development and simulation analysis of real-time, dual-load yard truck control systems for seaport container transshipment terminals. OR Spectrum, 32, 633-661.

Petering, M. E. H. (2011). Decision support for yard capacity, fleet composition, truck substitutability, and scalability issues at seaport container terminals. Transportation Research Part E, 47(1), 85-103.

Petering, M. E. H. (2015). Real-time container storage location assignment at an RTG-based seaport container transshipment terminal: problem description, control system, simulation model, and penalty scheme experimentation. Flexible Services and Manufacturing Journal, 27(2), 351-381.

Petering, M. E. H., \& Murty, K. G. (2009). Effect of block length and yard crane deployment systems on overall performance at a seaport container transshipment terminal. Computers \& Operations Research, 36(5), 1711-1725.

Petering, M. E. H., Wu, Y., Li, W., Goh, M., \& de Souza, R. (2009). Development and simulation analysis of real-time yard crane control systems for seaport container transshipment terminals. OR Spectrum, 31(4), 801-835.

Saanen, Y. A., \& Dekker, R. (2006a). Intelligent stacking as way out of congested yards? part 1. Port Technology International 31, 87-92.

Saanen, Y. A., \& Dekker, R. (2006b). Intelligent stacking as way out of congested yards? part 2. Port Technology International 32, 80-86.

Stahlbock, R., \& Voß, S. (2008). Operations research at container terminals: a literature update. OR Spectrum, 30(1), 1-52.

Steenken, D., Voß, S., \& Stahlbock, R. (2004). Container terminal operation and operations research - a classification and literature review. OR Spectrum, 26(1), 3-49.

Tao, Y., \& Lee, C.-Y. (2015). Joint planning of berth and yard allocation in transshipment terminals using multi-cluster stacking strategy. Transportation Research Part E, 83, 34-50

van Asperen, E., Borgman, B., \& Dekker, R. (2013). Evaluating impact of truck announcements on container stacking efficiency. Flexible Services and Manufacturing Journal, 25(4), 543-556.

Zhen, L. (2013). Yard template planning in transshipment hubs under uncertain berthing time and position. Journal of the Operational Research Society, 64, 1418-1428.

Zhen, L. (2014). Container yard template planning under uncertain maritime market. Transportation Research Part E, 69, 199-217.

Zhen, L. (2016). Modeling of yard congestion and optimization of yard template in container ports. Transportation Research Part B, 90, 83-104.

Zhen, L., Chew, E. P., \& Lee, L. H. (2011). An integrated model for berth template and yard template planning in transshipment hubs. Transportation Science, 45(4), 483-504.

Zhen, L., Xu, Z., Wang, K., \& Ding, Y. (2016). Multi-period yard template planning in container terminals. Transportation Research Part B, http://dx.doi.org/10.1016/j.trb.2015.12.006. 


\section{Figure captions}

Figure 1. Bird's eye view of a land-scarce, transshipment container terminal.

Figure 2. Layout of the 2-berth terminal in Setting 1 (bottom). Illustration of dispersion levels for containers loaded onto liner services with home berth 1 (top).

Figure 3. Layout of the 6-berth terminal in Setting 2 (bottom). Illustration of dispersion levels for containers loaded onto liner services with home berth 5 (top).

Figure 4. GCR results for Experiment 1 Setting 1.

Figure 5. GCR results for Experiment 1 Setting 2.

Figure 6. Two possible yard templates for a terminal. Top: weekly vessel schedule. Middle: yard template based on yard partition \#1. Bottom: yard template based on yard partition \#4H.

Figure 7. Average performance of eleven yard partitions at the 2-berth terminals (top) and 6berth terminals (bottom). Among two YC deployment systems (restrictive or free), only the result with higher GCR is shown. Dark (light) points correspond to the restrictive (free) YC deployment system.

Figure 8. Effect of vessel berthing policy on optimal container dispersion level: 8-berth terminal in Setting 1 with less equipment (top) and 10-berth terminal in Setting 2 with less equipment (bottom).

Figure 9. Effect of YT traveling speed on optimal container dispersion level: 6-berth terminal in Setting 2 with less equipment.

\section{Table captions}

Table 1. Objectives for container storage location assignment at a transshipment terminal (Petering, 2015).

Table 2. The real-time container storage algorithm (Petering, 2015).

Table 3. Detailed results for Experiment 1, Setting 1, 8-berth terminal, less equipment, restrictive $\mathrm{YC}$ deployment system, " $\mathrm{C}+\mathrm{D}$ " penalty regime.

Table 4. Mathematical model for creating a yard template.

Table 5. Yard partitions considered in Experiment 2.

Table 6. GCR results for Experiment 2: 2-berth terminals.

Table 7. GCR results for Experiment 2: 6-berth terminals.

Table 8. Detailed results for Experiment 2: 6-berth terminal, less equipment, penalty regime $\mathrm{C}$.

Table 9. Effect of vessel berthing policy on performance of penalty regimes: 6-berth terminal in Setting 2 with less equipment.

Table 10. Effect of vessel berthing policy on performance of yard partitions: 6-berth terminal, Setting 2, less equipment, restrictive YC deployment system, no penalty regime.

Table 11. Effect of YT traveling speed on performance of penalty regimes: 6-berth terminal in Setting 2 with less equipment. 


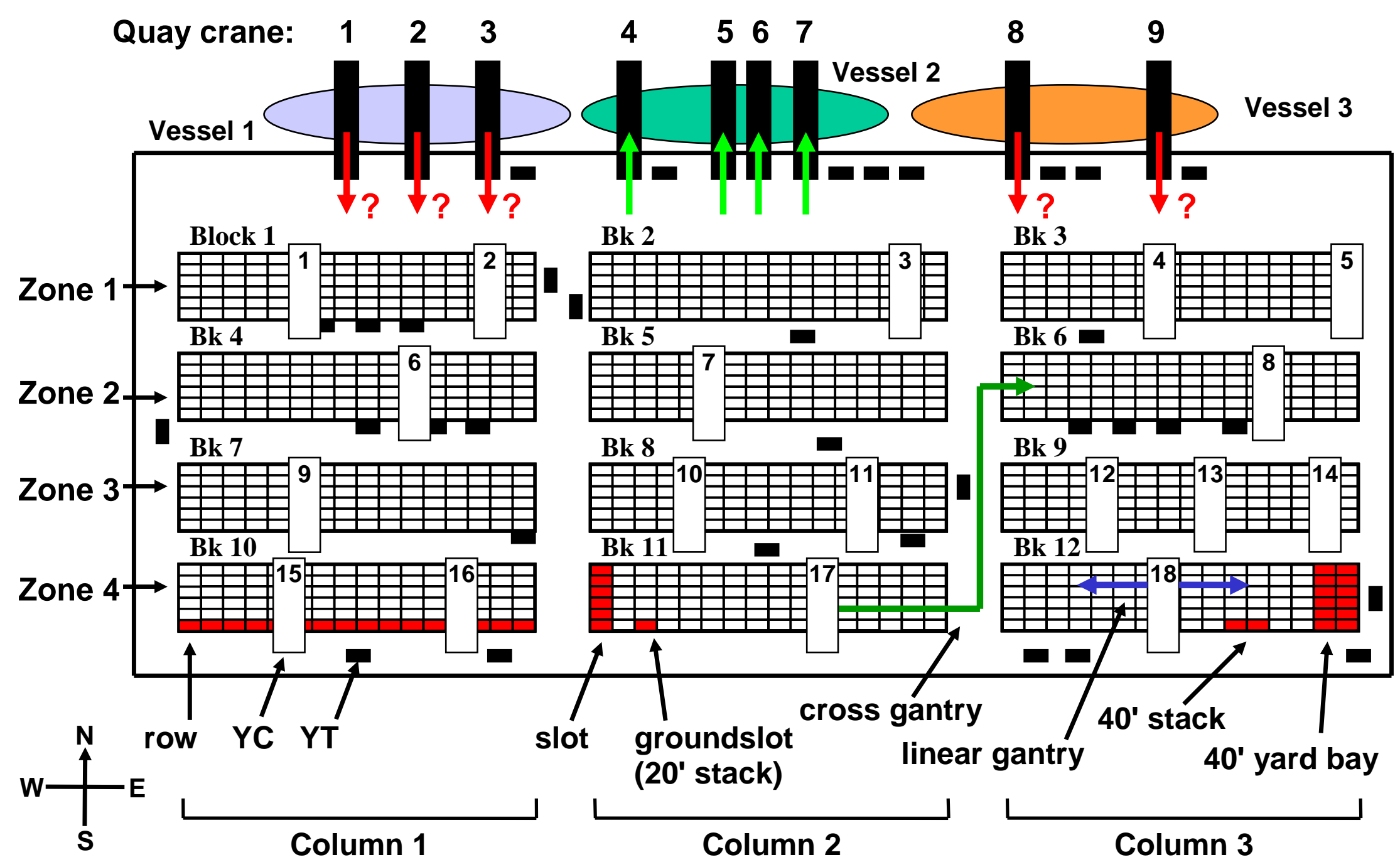

Figure 1. Bird's eye view of a land-scarce, transshipment container terminal. 
Preferred storage territory for containers

loaded onto liner services calling at berth 1:

Dispersion level 0:

Dispersion level 1:

Dispersion level 2:

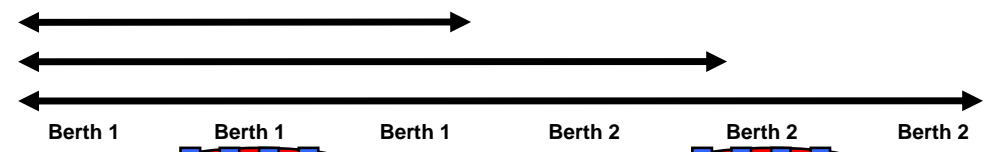

Zone 1
Zone 2
Zone 3
Zone 4
Zone 5

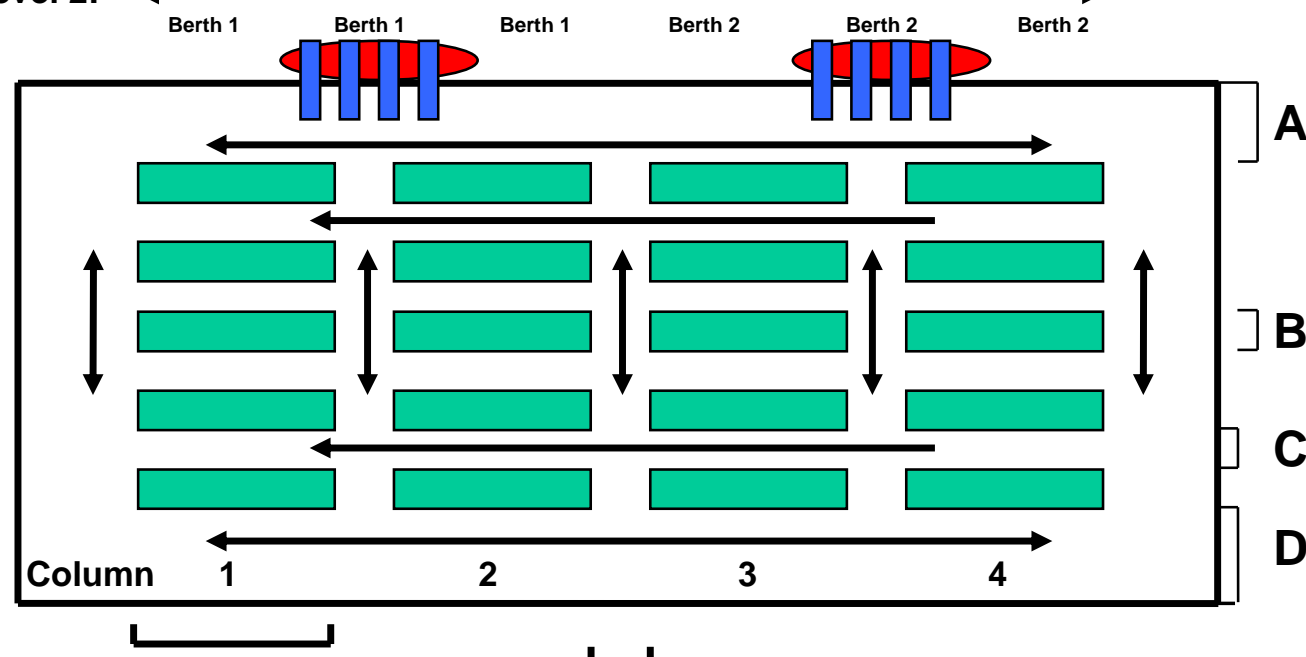

42 slots $=$

40 meters

A: 60 meters

273 meters

B: 17 meters

C: 13 meters

4

D: 30 meters

\section{0 meters}

\section{Terminal is $1292 \mathrm{~m}$ long $\mathrm{x} 227 \mathrm{~m}$ wide}

Figure 2. Layout of the 2-berth terminal in Setting 1 (bottom). Illustration of dispersion levels for containers loaded onto liner services with home berth 1 (top). 
Preferred storage territory for containers

loaded onto liner services calling at berth 5:

Dispersion level 0:

Dispersion level 1:

Dispersion level 2:

Dispersion level 3:

Dispersion level 4:

Dispersion level 5:

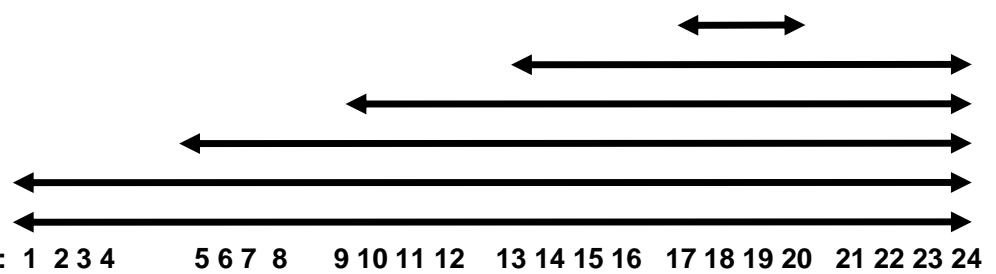

QC: 1234

$\begin{array}{llllllll}5678 & 9101112 & 13141516 & 17181920 & 21222324\end{array}$

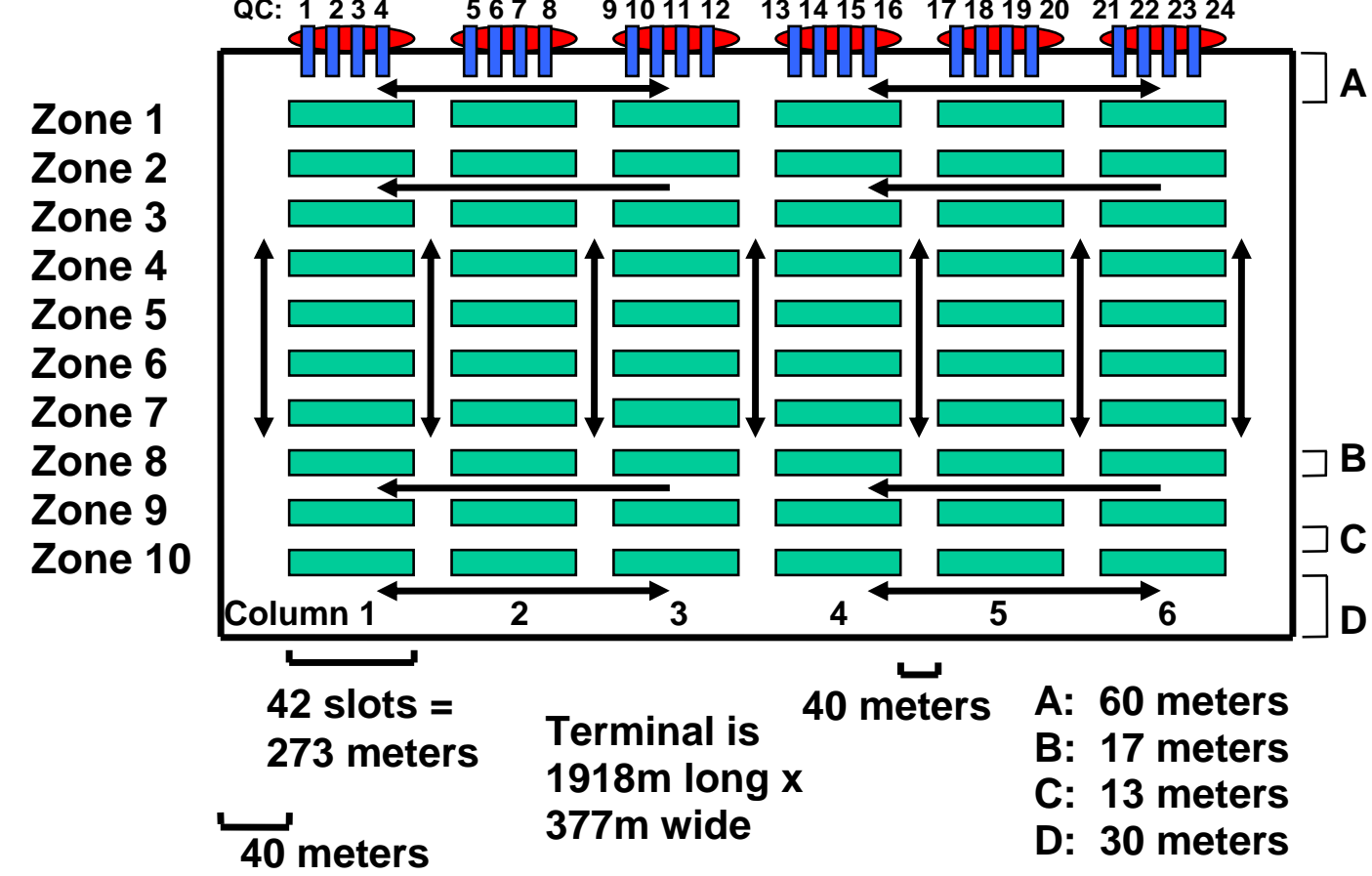

Figure 3. Layout of the 6-berth terminal in Setting 2 (bottom). Illustration of dispersion levels for containers loaded onto liner services with home berth 5 (top). 


\section{Less Equipment}

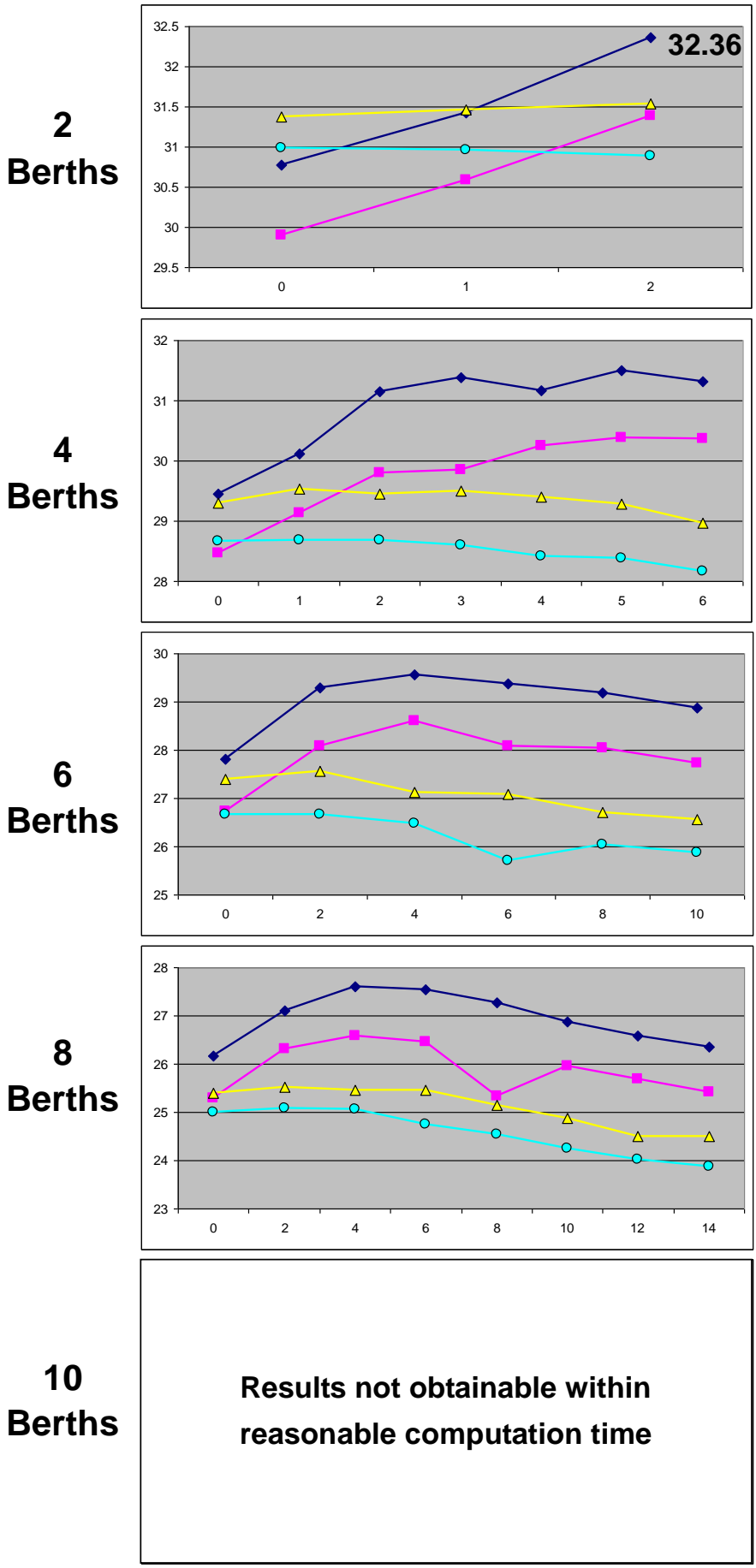

More Equipment
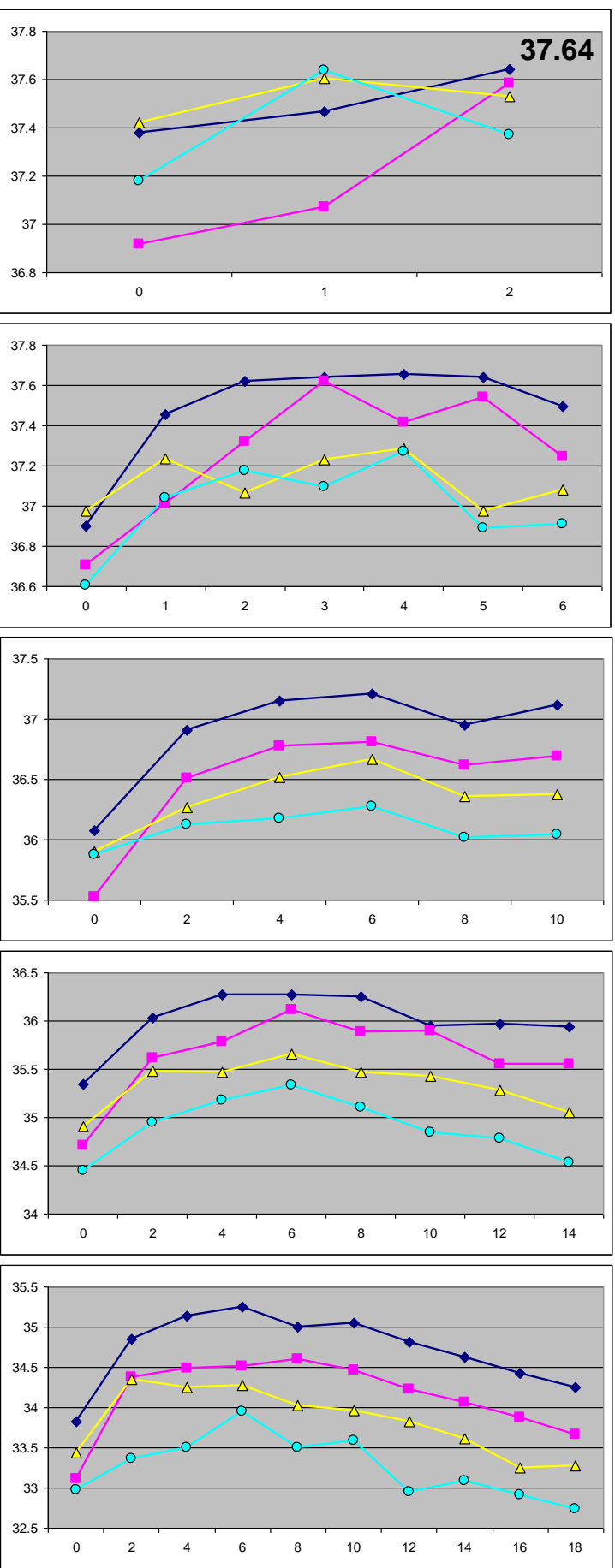

Penalty regime

Inter-block YC moves

$X$-axis: dispersion level

Y-axis: GCR (QC lifts/hr)

\begin{tabular}{r|cc} 
(YC deployment system $)$ & $\mathrm{C}+\mathrm{D}$ & None \\
\hline Restricted & $\diamond$ & \\
Free & $\triangle$ & 0
\end{tabular}

Figure 4. GCR results for Experiment 1 Setting 1. 


\section{Less Equipment}
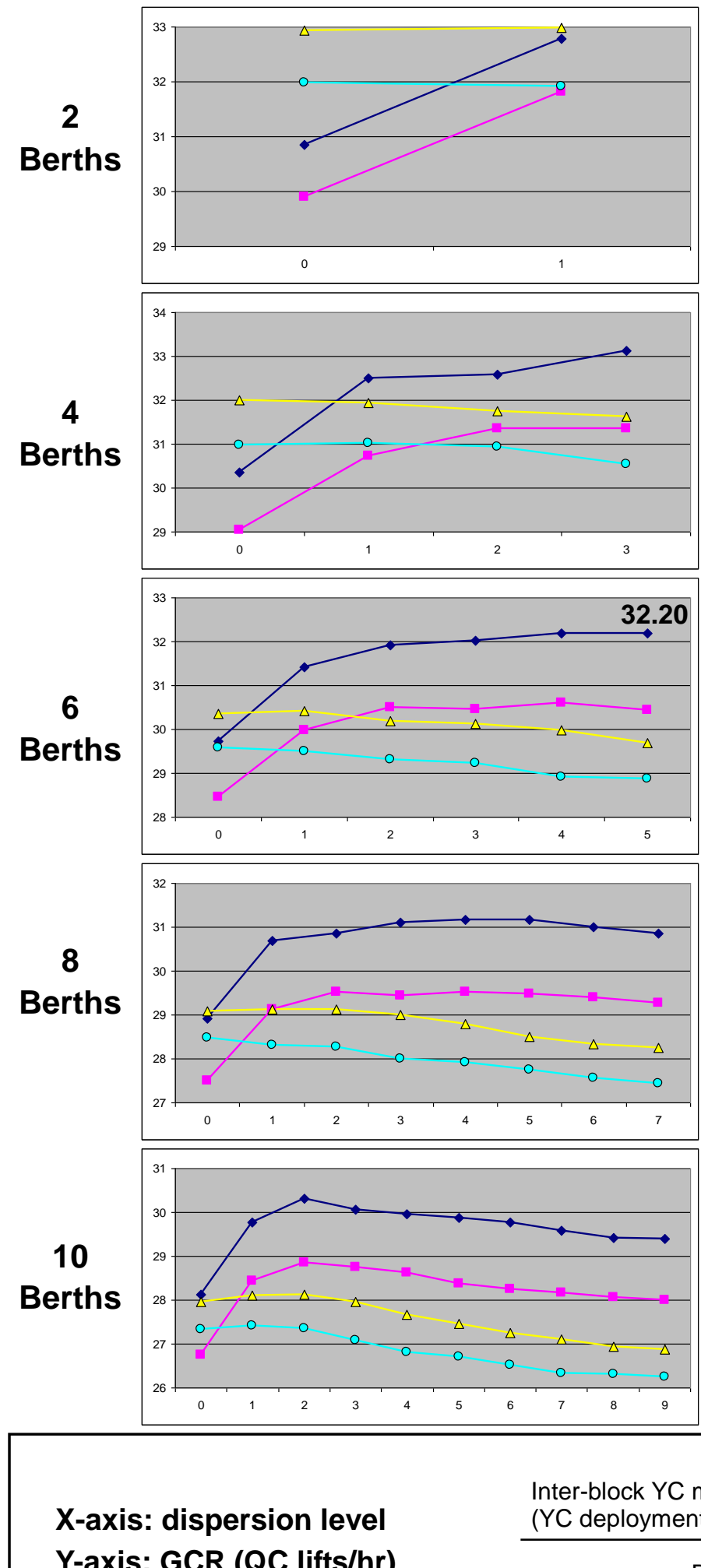

Y-axis: GCR (QC lifts/hr)

Figure 5. GCR results for Experiment 1 Setting 2.

\section{More Equipment}
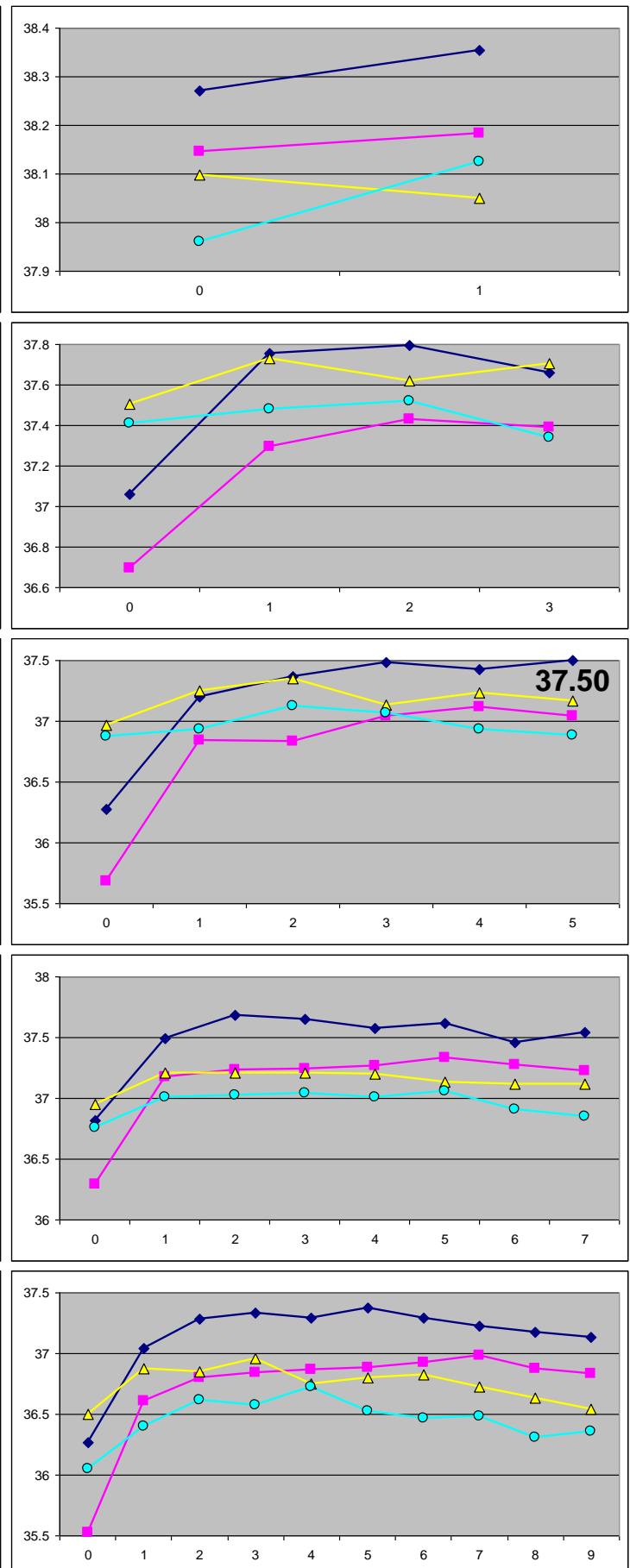

Penalty regime

Inter-block YC moves

(YC deployment system) $\quad$ C + D None

Restricted

Free

$\triangle$ 

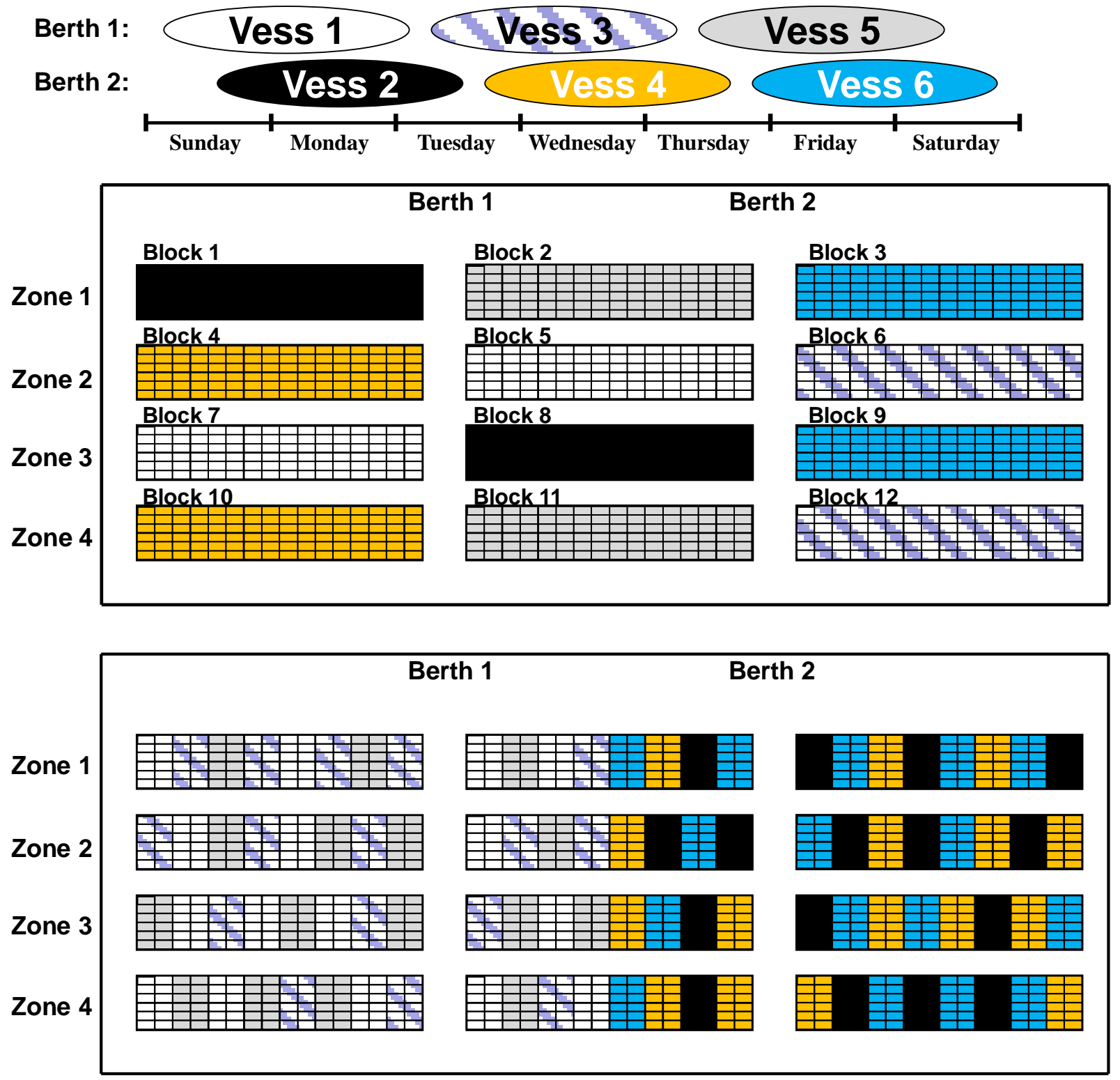

Figure 6. Two possible yard templates for a terminal. Top: weekly vessel schedule. Middle: yard template based on yard partition \#1. Bottom: yard template based on yard partition \#4H. 

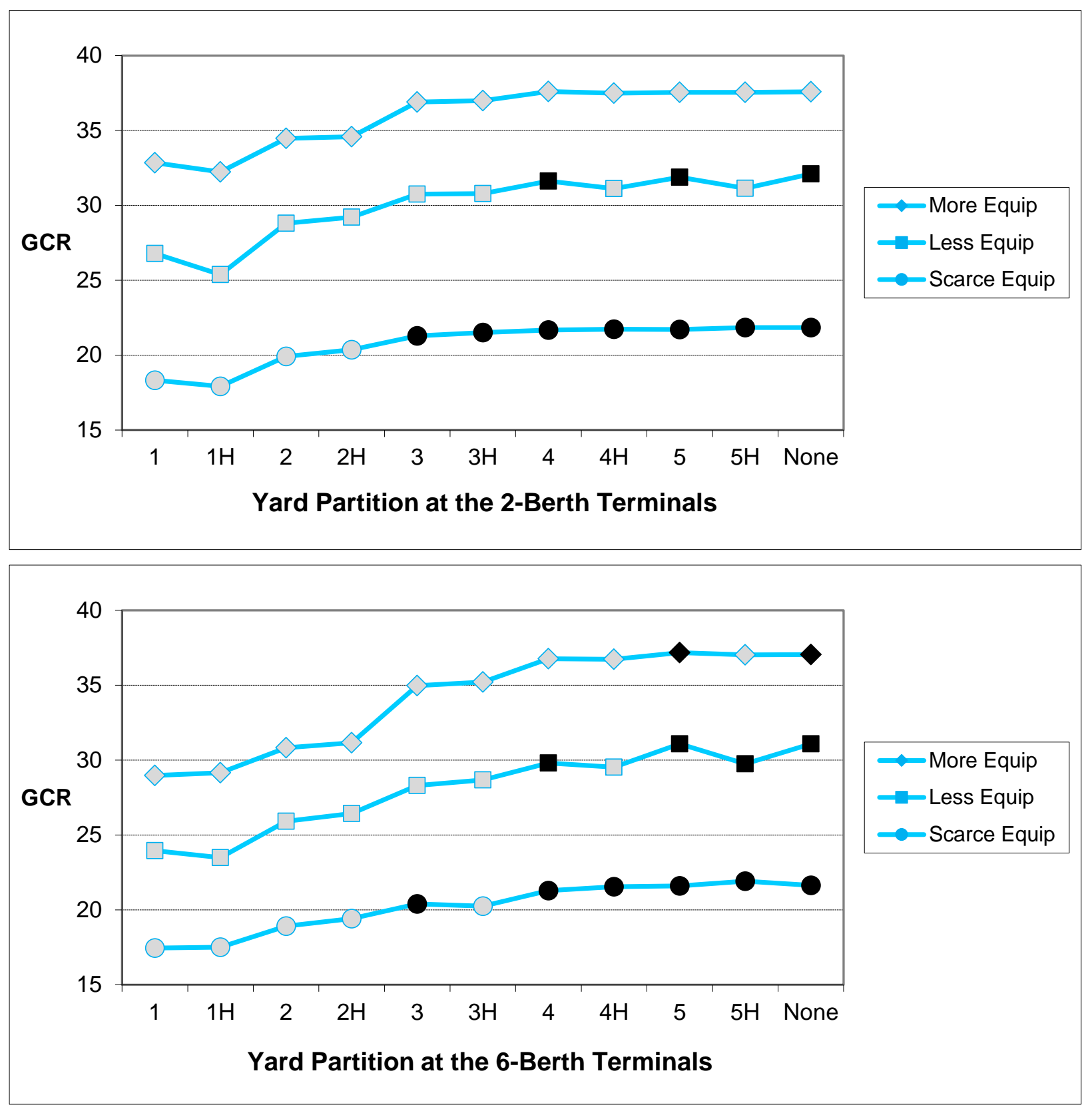

Figure 7. Average performance of eleven yard partitions at the 2-berth terminals (top) and 6-berth terminals (bottom). Among two YC deployment systems (restrictive or free), only the result with higher GCR is shown. Dark (light) points correspond to the restrictive (free) YC deployment system. 

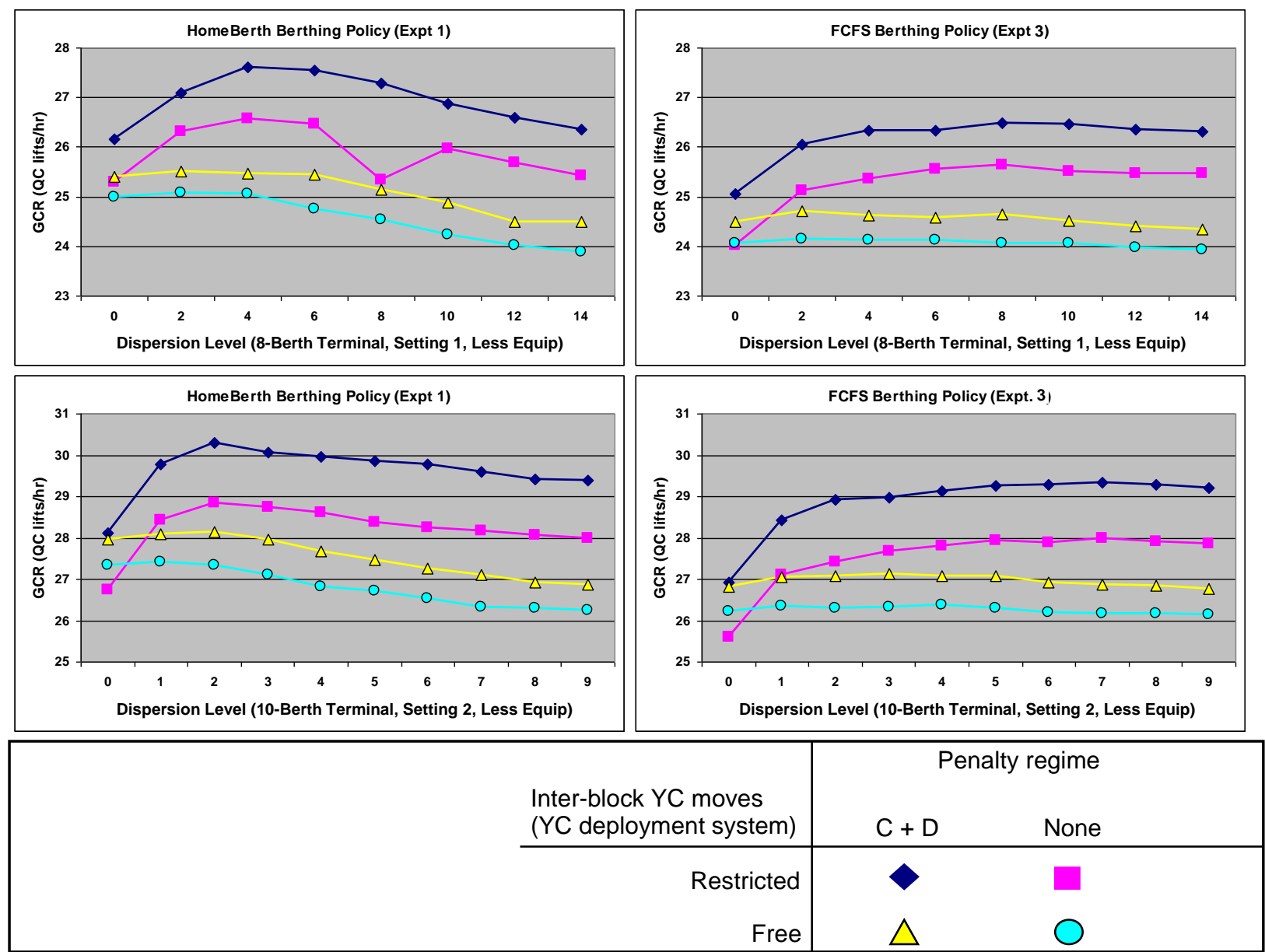

Figure 8. Effect of vessel berthing policy on optimal container dispersion level: 8-berth terminal in Setting 1 with less equipment (top) and 10-berth terminal in Setting 2 with less equipment (bottom). 

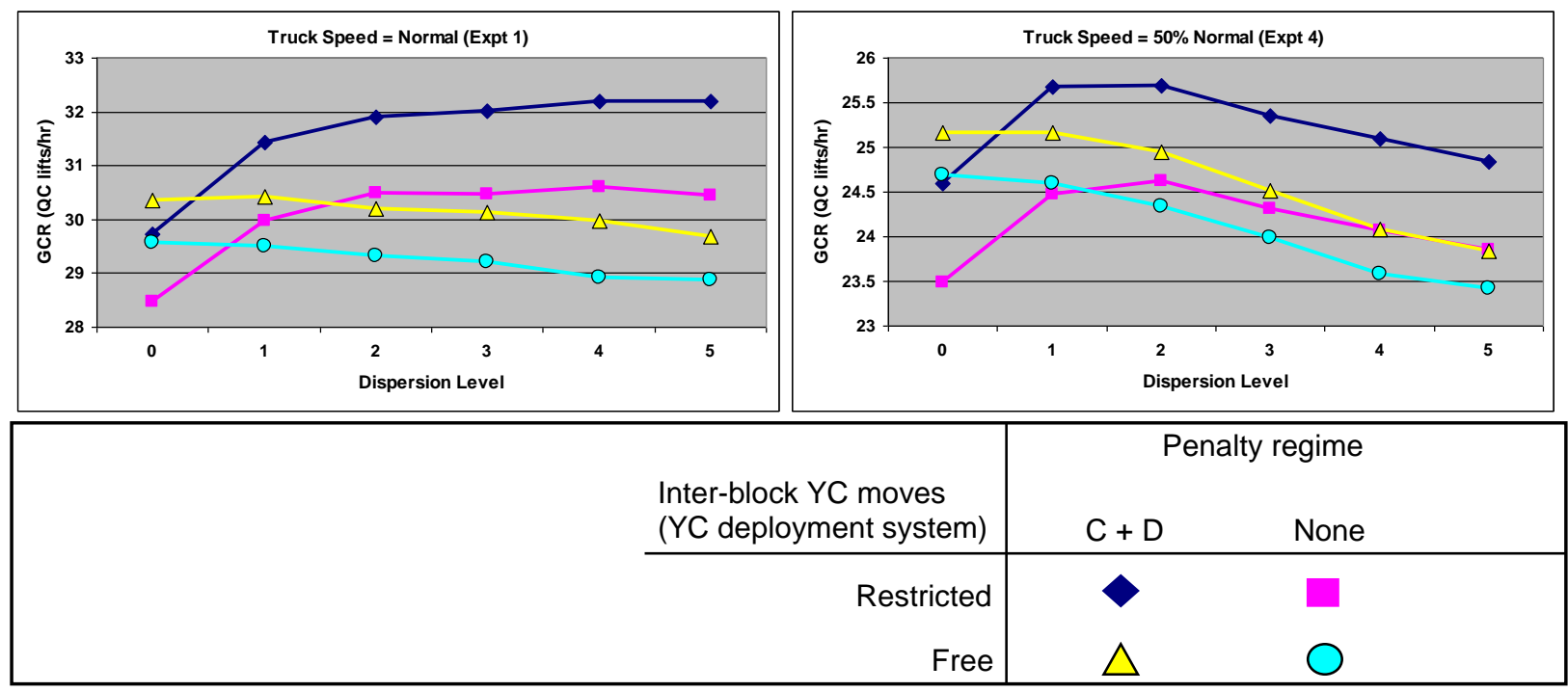

Figure 9. Effect of YT traveling speed on optimal container dispersion level: 6-berth terminal in Setting 2 with less equipment. 
Table 1. Objectives for container storage location assignment at a transshipment terminal (Petering, 2015).

\begin{tabular}{cl}
\hline Objective & Description \\
\hline A & Minimize container travel distance from quay to yard during unloading \\
B & Minimize container travel distance from yard to quay during loading (anticipated) \\
C & $\begin{array}{l}\text { Minimize YT congestion (i.e. maximize YC availability) in the vicinity of container } \\
\text { storage locations when containers are being stored }\end{array}$ \\
D & $\begin{array}{l}\text { Minimize YT congestion (i.e. maximize YC availability) in the vicinity of container } \\
\text { retrieval locations when containers are being retrieved (anticipated). }\end{array}$ \\
\hline
\end{tabular}


Table 2. The real-time container storage algorithm (Petering, 2015).

\begin{tabular}{cl}
\hline Step & Procedure \\
\hline 0 & $\begin{array}{l}\text { Check the yard to determine if the arriving container should be classified as non-trailblazing or } \\
\text { trailblazing. If it is non-trailblazing (trailblazing), the container is assigned to a partially full (an empty) } \\
\text { yard stack and the algorithm terminates (continues to step 1). See Sect. 2.2 of Petering (2015) for details. }\end{array}$ \\
\hline 1 & $\begin{array}{l}\text { If the parameter simult20 = Yes and the container is the first of two 20' 'sister" containers to be unloaded } \\
\text { consecutively by the same QC onto the same YT, STOP. The storage location for this container is not } \\
\text { decided now but instead is decided simultaneously with its sister container, immediately after the sister } \\
\text { container is discharged onto the same YT (Sect. 5.3 of Petering, 2015). Otherwise, continue to step 2. }\end{array}$ \\
\hline 2 & $\begin{array}{l}\text { Identify container length (20' or 40') and make a list of all empty yard stacks (i.e. candidate stacks) that } \\
\text { can accommodate a container of that length. }\end{array}$ \\
\hline 3 & $\begin{array}{l}\text { If container is 20' long and there are fewer than threshold40 empty 40' stacks in the yard, delete all 20' } \\
\text { stacks in the list of candidate stacks that are part of an empty 40' stack. This helps to conserve empty 40' } \\
\text { stacks for future containers. If the list becomes empty, do not delete any stacks from the list. }\end{array}$ \\
\hline 4 & $\begin{array}{l}\text { Delete all stacks in the list of candidate stacks that do not agree with the container dispersion level } \\
\text { being used (if applicable). If the list becomes empty, do not delete any stacks from the list. }\end{array}$ \\
\hline 5 & $\begin{array}{l}\text { Delete all stacks in the list of candidate stacks that do not agree with the yard template being used } \\
\text { (if applicable). If the list becomes empty, do not delete any stacks from the list. }\end{array}$ \\
\hline 6 & $\begin{array}{l}\text { Observe the real-time state of the terminal and give each storage block in the yard a penalty score based on } \\
\text { the penalty weights associated with ten penalty components (Table 4 in Petering, 2015). Assign to each } \\
\text { candidate stack the penalty score of the block in which it resides. }\end{array}$ \\
\hline 7 & $\begin{array}{l}\text { Select the candidate stack with the lowest penalty score. Break ties randomly. This stack is the storage } \\
\text { location assigned to the container. }\end{array}$ \\
\hline
\end{tabular}


Table 3. Detailed results for Experiment 1, Setting 1, 8-berth terminal, less equipment, restrictive YC deployment system, “C + D" penalty regime.

\begin{tabular}{|c|c|c|c|c|c|c|c|c|c|c|c|c|c|c|c|c|c|c|c|c|}
\hline $\begin{array}{r}\text { Disper } \\
\text { Leve }\end{array}$ & $K$ & $\begin{array}{l}\text { th } \\
\mathrm{c}\end{array}$ & $\begin{array}{l}\text { ssl } \\
\text { riv }\end{array}$ & & & & & $\begin{array}{l}\mathrm{QC} \\
\text { VaitU }\end{array}$ & $\begin{array}{l}\overline{Q C} \\
\text { laitL }\end{array}$ & $\begin{array}{l}\mathrm{C} \\
\text { ait }\end{array}$ & $\begin{array}{c}\text { YC } \\
\text { Prod }\end{array}$ & $\begin{array}{l}\text { YT } \\
\text { Prod }\end{array}$ & $\begin{array}{l}\mathrm{YT} \\
\text { ravYS }\end{array}$ & $\begin{array}{c}\text { YT } \\
\text { WaitYS }\end{array}$ & $\begin{array}{c}\text { YT } \\
\text { TravYR }\end{array}$ & $\begin{array}{c}\text { YT } \\
\text { VaitY }\end{array}$ & $\begin{array}{l}\mathrm{YT} \\
\operatorname{ravQL}\end{array}$ & $\begin{array}{c}\text { YT } \\
\text { Total }\end{array}$ & $\begin{array}{l}\text { Cont } \\
\text { NaitS }\end{array}$ & TravQ \\
\hline- & & .9 & $\overline{94}$ & 18 & & & & & & & & & & 220 & & 225 & $\overline{0}$ & & & \\
\hline 2 & & .96 & & .24 & & & & & & & & & & & & & & & & \\
\hline 4 & 2 & .95 & 90.2 & .26 & & 6 & & .0 & & & & & & .1 & & .2 & & & & 20 \\
\hline 6 & & .95 & 0.8 & .26 & & & & 0 & & .2 & & & & .1 & & .1 & & & & 62 \\
\hline$\xi$ & & .95 & 2.0 & .23 & & & & 0 & & .2 & & & .1 & .1 & & .188 & & & & 3.03 \\
\hline & & .95 & 3.3 & .23 & & & & .0 & .2 & .2 & & & & .1 & & 182 & .1 & & .15 & .41 \\
\hline & & .96 & 3.2 & .22 & & & & .07 & .2 & .28 & & 7 & .19 & .15 & & 177 & 151 & .74 & 3.74 & .66 \\
\hline & 26.36 & .96 & 93.8 & .22 & $45 \%$ & $8 \%$ & 212 & .075 & .218 & 293 & 9.85 & 5.12 & 187 & 152 & .075 & 177 & .157 & .748 & 3.72 & .79 \\
\hline
\end{tabular}

GCR = gross crane rate (total QC lifts / total hours of QC time beside a busy berth)

Berth Occ $=$ berth occupancy (average fraction of berths occupied at any instant)

Vessl Arriv = number of vessel arrivals at the port

BOA Rate $=$ the berth-on-arrival rate, i.e. the fraction of vessels that are able to berth upon their arrival

$\% \mathrm{Vol}=$ average percentage of total yard storage volume occupied at any instant

$\%$ Area $=$ average percentage of total yard storage area occupied at any instant

QCLifts = total number of QC lifts made

QC WaitU = fraction of time that an average QC spends waiting for YTs to appear during unloading (averaged over entire simulation run)

QC WaitL = fraction of time that an average QC spends waiting for YTs to appear during loading (averaged over entire simulation run)

QC Wait = QC WaitU + QC WaitL

YC Prod = average yard crane productivity (total YC lifts / total hours of YC time)

YT Prod = average yard truck productivity (total number of containers placed on YT trailers / total hours of active YT time)

YT TravYS = fraction of time that an average YT spends traveling towards the yard with container(s) needing to be stored (averaged over entire simulation run) YT WaitYS = fraction of time that an average YT spends waiting for YC service in the yard after reaching the slot in the yard where a container is to be stored YT TravYR = fraction of time that an average YT spends traveling towards the yard to retrieve container(s) from the yard (averaged over entire simulation run) YT WaitYR = fraction of time that an average YT spends waiting for YC service in the yard after reaching the slot in the yard where a container is to be retrieved $\mathrm{YT}$ TravQL = fraction of time that an average YT spends traveling towards the quay while carrying container(s) that will be loaded (avg. over entire simulation) YT Total $=$ YT TravYS + YT WaitYS + YT TravYR + YT WaitYR + YT TravQL

Cont WaitS = time that an avg. container spends waiting for YC service in the yard after the YT reaches slot in the yard where container will be stored (minutes) Cont TravQ = time that an avg. container spends traveling towards the quay (i.e. from yard to quay) on a YT prior to being loaded (minutes) 
Table 4. Mathematical model for creating a yard template.

\begin{tabular}{lll}
\hline \multicolumn{1}{c}{ Indices } & \\
\hline$r$ & yard region & $(r=1$ to $R)$ \\
$s, t$ & groundslot (i.e. 20' stack) number & $(s, t=1$ to $S)$ \\
$v, w$ & vessel (i.e. liner service) & $(v, w=1$ to $V)$ \\
\hline
\end{tabular}

\section{Parameters}

$V \quad$ Number of vessels (i.e. liner services) visiting the terminal each week (integer, $>0$ ).

$M_{v} \quad$ Minimum number of groundslots needed for storing the containers loaded onto vessel $v$ (integer, $>0$ ).

$S \quad$ Number of groundslots in the yard (integer, $>0$ ).

$R \quad$ Number of regions into which the yard is divided as specified by the yard partition (integer, $>0$ ).

$S_{r} \quad$ Number of groundslots in yard region $r$ as specified by the yard partition (integer, $>0$ ).

$I_{r, s} \quad=1$ if yard region $r$ contains groundslot $s$ (binary).

$T_{v, w} \quad$ Expected time overlap for vessels $v$ and $w$ at the terminal each week. If vessels $v$ and $w$ are expected to be at the terminal during overlapping time intervals, $T_{v, w}$ equals the overlap duration in minutes. If vessels $v$ and $w$ are expected to be at the terminal during non-overlapping time intervals, $T_{v, w}$ equals the negative of the duration (in minutes) of the smaller of the two intervals separating the expected departure of one vessel from the expected arrival of the other vessel, divided by 100 (real).

Sep Minimum required separation distance (in slots) between two YCs (= 8; see Fig. 2 in Petering, 2015).

$C_{s, t} \quad=1$ if groundslots $s$ and $t$ are in the same block and are less than Sep slots apart and $s \neq t$ (binary).

$Z_{s, t} \quad=1$ if groundslots $s$ and $t$ are in the same yard zone and $s \neq t$ (binary).

$D_{s, v} \quad$ Distance in meters from groundslot $s$ to the expected berthing position of vessel $v$ (real, $>0$ ).

$W_{1}, W_{2} \quad$ Weights for objective function components (real).

\section{Decision variables}

$X_{r, v} \quad=1$ if region $r$ is a preferred storage location (PSL) for containers loaded onto vessel $v$ (binary).

$Y_{s, v} \quad=1$ if groundslot $s$ is a PSL for containers loaded onto vessel $v$ (binary).

\section{Mathematical program}

Minimize: $\quad \sum_{s=1}^{S}\left(\left(\sum_{t: C_{s, t}=1} \sum_{v=1}^{V} \sum_{w=1}^{V} T_{v, w} Y_{s, v} Y_{t, w}\right)+W_{1}\left(\sum_{t: Z_{s, t}=1} \sum_{v=1}^{V} \sum_{w=1}^{V} T_{v, w} Y_{s, v} Y_{t, w}\right)+W_{2}\left(\sum_{v=1}^{V} D_{s, v} Y_{s, v}\right)\right)$

Subject to: $\quad \sum_{v=1}^{V} X_{r, v} \geq 1 \quad \forall r$

$\sum_{r=1}^{R} S_{r} X_{r, v} \geq M_{v} \quad \forall v$

$S_{r} X_{r, v}=\sum_{s: I_{r, s}=1} Y_{s, v} \quad \forall r \forall v$ 
Table 5. Yard partitions considered in Experiment 2.

\begin{tabular}{|l|cc|cc|cc|cc|cc|}
\hline Partition number & 1 & $1 \mathrm{H}$ & 2 & $2 \mathrm{H}$ & 3 & $3 \mathrm{H}$ & 4 & $4 \mathrm{H}$ & 5 & $5 \mathrm{H}$ \\
\hline Region size (number of 40' yard bays) & 21 & 21 & 7 & 7 & 3 & 3 & 1 & 1 & $1 / 6$ & $1 / 6$ \\
\hline Region size (number of 40' stacks) & 126 & 126 & 42 & 42 & 18 & 18 & 6 & 6 & 1 & 1 \\
\hline $\begin{array}{l}\text { Number of regions allocated to each } \\
\text { liner service (2-berth terminals) }\end{array}$ & 2 & 2 & 6 & 6 & 14 & 14 & 42 & 42 & 252 & 252 \\
\hline $\begin{array}{l}\text { Number of regions allocated to each } \\
\text { liner service (6-berth terminals) }\end{array}$ & 1 & 1 & 3 & 3 & 7 & 7 & 21 & 21 & 126 & 126 \\
\hline
\end{tabular}


Table 6. GCR results for Experiment 2: 2-berth terminals.

\begin{tabular}{|c|c|c|c|c|c|c|c|c|c|c|c|c|c|c|}
\hline Fleet & YC & Penalty & & & & & ro & d Partit & tion & & & & & \\
\hline Size & Deploy & Regime & 1 & $1 H$ & 2 & $2 \mathrm{H}$ & 3 & $3 \mathrm{H}$ & 4 & $4 \mathrm{H}$ & 5 & $5 \mathrm{H}$ & None & Avg. \\
\hline Scarce & Restr. & None & 14.81 & 14.86 & 19.12 & 19.91 & 20.99 & 21.24 & 21.35 & 21.45 & 21.39 & 21.54 & 21.39 & 19.82 \\
\hline Equip. & & C & 15.34 & 15.38 & 19.79 & 20.62 & 21.57 & 21.75 & 21.98 & 22.00 & 22.04 & 22.11 & 22.29 & 20.44 \\
\hline 15 YCs & Free & None & 18.29 & 17.59 & 19.63 & 20.07 & 20.34 & 20.27 & 20.51 & 20.51 & 20.41 & 20.57 & 20.44 & 19.88 \\
\hline 24 YTs & & C & 18.35 & 18.23 & 20.17 & 20.63 & 20.81 & 20.85 & 20.97 & 21.00 & 20.97 & 21.05 & 21.04 & 20.37 \\
\hline Less & Restr. & None & 16.56 & 16.35 & 24.28 & 25.25 & 29.96 & 28.91 & 31.24 & 30.12 & 31.79 & 30.60 & 31.74 & 26.98 \\
\hline p. & & C & 17.01 & .95 & 2 & 26.37 & 30.58 & .11 & 31.99 & 30.94 & 31.94 & 31.12 & 32.44 & 27.71 \\
\hline 20 YCs & Free & None & 26.36 & 25.35 & 28.49 & 28.89 & 30.49 & 30.54 & 30.93 & 30.75 & 30.93 & 30.90 & 30.98 & 29.51 \\
\hline 40 YTs & & C & 27.21 & 25.37 & 29.10 & 29.51 & 30.98 & 31.02 & 31.32 & 31.46 & 31.38 & 31.35 & 31.36 & 30.00 \\
\hline More & Restr. & None & $\mid 21.29$ & 27.32 & 33.03 & 33.66 & 36.47 & 36.39 & 37.05 & 37.33 & 37.22 & 37.26 & 37.43 & 34.59 \\
\hline Equip. & & C & 27.45 & 27.34 & 33.29 & 33.96 & 36.83 & 36.63 & 37.41 & 37.10 & 37.29 & 37.30 & 37.49 & 34.74 \\
\hline 25 YCs & Free & None & 32.71 & 32.31 & 34.21 & 34.31 & 36.83 & 37.04 & 37.69 & 37.40 & 37.47 & 37.54 & 37.63 & 35.92 \\
\hline 72 YTs & & C & 32.96 & 32.15 & 34.73 & 34.84 & 36.96 & 36.94 & 37.51 & 37.54 & 37.60 & 37.54 & $37.52 \mid$ & 36.03 \\
\hline
\end{tabular}

++ $\quad$ Results for the restrictive YC deployment system in this column are copied from Petering (2015).

Shaded values indicate the better performing YC deployment system (on average) for a given fleet size and yard partition.

Darkly shaded values indicate the best performing scenario for each equipment fleet size. 
Table 7. GCR results for Experiment 2: 6-berth terminals.

\begin{tabular}{|c|c|c|c|c|c|c|c|c|c|c|c|c|c|c|}
\hline \multirow{2}{*}{$\begin{array}{l}\text { Fleet } \\
\text { Size }\end{array}$} & \multirow{2}{*}{\multicolumn{2}{|c|}{\begin{tabular}{|c} 
YC Penalty \\
Deploy Regime
\end{tabular}}} & & \multirow[b]{2}{*}{$1 \mathrm{H}$} & \multicolumn{6}{|c|}{ Yard Partition } & & \multirow[b]{2}{*}{$5 \mathrm{H}$} & \multirow{2}{*}{$\begin{array}{c}++ \\
\text { None }\end{array}$} & \multirow[b]{2}{*}{ Avg. } \\
\hline & & & & & & H & 3 & $3 \mathrm{H}$ & 4 & $\mathbf{H}$ & & & & \\
\hline \multirow{4}{*}{$\begin{array}{l}\text { Scarce } \\
\text { Equip. } \\
50 \text { YCs } \\
72 \text { YTs }\end{array}$} & & None & 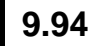 & 9.73 & 1 & & 20.01 & 19.86 & & 21.03 & 21.25 & 21.57 & |21.25 & 18.29 \\
\hline & & C & & & 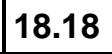 & 0 & 7 & & 8 & 2 & 5 & 7 & 4 & 19.10 \\
\hline & & one & $?$ & & 18.71 & 18 & 19.54 & 20.10 & 19.68 & 20 & 19.64 & 20 & 19.59 & 19.22 \\
\hline & & $\mathrm{C}$ & & & 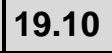 & & & & 8 & & 20.13 & & 20.23 & 19.65 \\
\hline \multirow{4}{*}{\begin{tabular}{|c|} 
Less \\
Equip. \\
60 YCs \\
120 YTs
\end{tabular}} & & 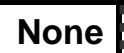 & & & & & & & & & & & & דם" \\
\hline & & & & & & & & & & & & & & .87 \\
\hline & & None & & & & 9 & & & .73 & 16 & 2 & 34 & .76 & .26 \\
\hline & & $\sqrt{2}$ & 24.13 & 23.91 & 26.33 & 2 & 28.57 & & 29.54 & 29.90 & 29.59 & & 29.73 & 27.95 \\
\hline \multirow{4}{*}{$\begin{array}{c}\text { More } \\
\text { Equip. } \\
70 \text { YCs } \\
216 \text { YTs }\end{array}$} & Restr. & None & 19.50 & 1 & 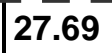 & 2 & & & & & & & 99 & \\
\hline & & C & |20.0 & & 28.93 & 29.88 & & & 36.70 & 35.71 & 37.20 & 36.69 & 37.10 & 31.87 \\
\hline & 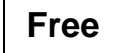 & . & & & 30.66 & & & & 14 & & 3 & 36.95 & 7.02 & 0.50 \\
\hline & & C & & 20.00 & 30.97 & 31.37 & 34.89 & 35.35 & 36.79 & & 37.09 & 37.08 & 36.86 & 34.16 \\
\hline
\end{tabular}

$++\quad$ Results for the restrictive YC deployment system in this column are copied from Petering (2015).

Shaded values indicate the better performing YC deployment system (on average) for a given fleet size and yard partition.

Darkly shaded values indicate the best performing scenario for each equipment fleet size.

Dashed rectangles: Detailed results for these experiments are displayed in Table 8.

Dotted rectangle: More detailed results for these experiments are displayed in Table 10. 


\begin{tabular}{|c|c|c|c|c|c|c|c|c|c|c|c|c|c|}
\hline $\begin{array}{c}\text { YC } \\
\text { Deploy }\end{array}$ & $\begin{array}{c}\text { Yard } \\
\text { Partition }\end{array}$ & GCR & $\begin{array}{c}\text { YC } \\
\text { Moves }\end{array}$ & $\begin{array}{l}\text { YC } \\
\text { Idle }\end{array}$ & $\begin{array}{c}\text { YC } \\
\text { Gantry }\end{array}$ & $\begin{array}{c}\text { YT } \\
\text { WaitYS }\end{array}$ & $\begin{array}{c}\text { YT } \\
\text { TravQL }\end{array}$ & $\begin{array}{c}\text { Cont } \\
\text { TravY }\end{array}$ & $\begin{array}{c}\text { Cont } \\
\text { WaitS }\end{array}$ & $\begin{array}{c}\text { Cont } \\
\text { WaitR }\end{array}$ & $\begin{array}{c}\text { Cont } \\
\text { TravQ }\end{array}$ & $\begin{array}{l}\text { Avg \# } \\
\text { YT-Y }\end{array}$ & $\begin{array}{l}\text { Avg \# } \\
\text { YT-Q }\end{array}$ \\
\hline \multirow{6}{*}{ Restrict } & $\begin{array}{c}1 \\
1 \mathrm{H}\end{array}$ & $\begin{array}{l}11.65 \\
11.58\end{array}$ & $\begin{array}{l}0 \\
0\end{array}$ & $\begin{array}{l}.707 \\
.708\end{array}$ & $\begin{array}{l}.076 \\
.076\end{array}$ & $\begin{array}{l}.659 \\
.665\end{array}$ & $\begin{array}{l}.047 \\
.035\end{array}$ & $\begin{array}{l}2.65 \\
2.64\end{array}$ & $\begin{array}{l}34.0 \\
34.5\end{array}$ & $\begin{array}{l}966 \\
981\end{array}$ & $\begin{array}{l}2.52 \\
1.89\end{array}$ & $\begin{array}{l}109.1 \\
110.5\end{array}$ & $\begin{array}{c}10.9 \\
9.5\end{array}$ \\
\hline & $\begin{array}{c}2 \\
2 \mathrm{H}\end{array}$ & $\begin{array}{l}21.69 \\
23.30\end{array}$ & $\begin{array}{l}0 \\
0\end{array}$ & $\begin{array}{l}.518 \\
.491\end{array}$ & $\begin{array}{l}.099 \\
.102\end{array}$ & $\begin{array}{l}.388 \\
.377\end{array}$ & $\begin{array}{l}.089 \\
.072\end{array}$ & $\begin{array}{l}2.65 \\
2.65\end{array}$ & $\begin{array}{l}11.1 \\
10.0\end{array}$ & $\begin{array}{l}399 \\
345\end{array}$ & $\begin{array}{l}2.54 \\
1.92\end{array}$ & $\begin{array}{l}94.6 \\
95.2\end{array}$ & $\begin{array}{l}25.4 \\
24.8\end{array}$ \\
\hline & $\begin{array}{c}3 \\
3 \mathrm{H}\end{array}$ & $\begin{array}{l}27.49 \\
25.55\end{array}$ & $\begin{array}{l}0 \\
0\end{array}$ & $\begin{array}{l}.413 \\
.448\end{array}$ & $\begin{array}{l}.117 \\
.112\end{array}$ & $\begin{array}{l}.277 \\
.330\end{array}$ & $\begin{array}{l}.112 \\
.079\end{array}$ & \begin{tabular}{|l|}
2.65 \\
2.65
\end{tabular} & $\begin{array}{l}6.3 \\
8.1\end{array}$ & $\begin{array}{l}247 \\
284\end{array}$ & $\begin{array}{l}2.55 \\
1.92\end{array}$ & $\begin{array}{l}84.2 \\
90.4\end{array}$ & $\begin{array}{l}35.1 \\
29.3\end{array}$ \\
\hline & $\begin{array}{c}4 \\
4 \mathrm{H}\end{array}$ & $\begin{array}{l}30.22 \\
28.76\end{array}$ & $\begin{array}{l}0 \\
0\end{array}$ & $\begin{array}{l}.386 \\
.401\end{array}$ & $\begin{array}{l}.125 \\
.122\end{array}$ & $\begin{array}{l}.208 \\
.263\end{array}$ & $\begin{array}{l}.118 \\
.087\end{array}$ & $\begin{array}{l}2.65 \\
2.65\end{array}$ & $\begin{array}{l}4.5 \\
5.9\end{array}$ & $\begin{array}{l}190 \\
217\end{array}$ & $\begin{array}{l}2.56 \\
1.93\end{array}$ & $\begin{array}{l}74.2 \\
82.9\end{array}$ & $\begin{array}{l}40.4 \\
34.2\end{array}$ \\
\hline & $\begin{array}{c}5 \\
5 \mathrm{H}\end{array}$ & $\begin{array}{l}31.56 \\
30.24\end{array}$ & $\begin{array}{l}0 \\
0\end{array}$ & $\begin{array}{l}.378 \\
.385\end{array}$ & $\begin{array}{l}.128 \\
.127\end{array}$ & $\begin{array}{l}.183 \\
.228\end{array}$ & $\begin{array}{l}.119 \\
.090\end{array}$ & $\begin{array}{l}2.66 \\
2.66\end{array}$ & $\begin{array}{l}3.9 \\
5.0\end{array}$ & $\begin{array}{l}164 \\
189\end{array}$ & $\begin{array}{l}2.56 \\
1.94\end{array}$ & \begin{tabular}{|l|}
69.4 \\
77.9
\end{tabular} & $\begin{array}{l}41.5 \\
36.7\end{array}$ \\
\hline & None & 31.53 & 0 & .377 & .129 & .173 & .119 & 2.65 & 3.7 & 165 & 2.56 & 68.6 & 42.3 \\
\hline \multirow{7}{*}{ Free } & $\begin{array}{c}1 \\
1 \mathrm{H}\end{array}$ & $\begin{array}{l}24.13 \\
23.91\end{array}$ & $\begin{array}{l}64,851 \\
64,790\end{array}$ & $\begin{array}{l}.412 \\
.416\end{array}$ & $\begin{array}{l}.187 \\
.186\end{array}$ & $\begin{array}{l}.318 \\
.353\end{array}$ & $\begin{array}{l}.099 \\
.075\end{array}$ & $\begin{array}{l}2.65 \\
2.66\end{array}$ & $\begin{array}{l}8.2 \\
9.2\end{array}$ & $\begin{array}{l}323 \\
333\end{array}$ & $\begin{array}{l}2.55 \\
1.96\end{array}$ & $\begin{array}{l}90.9 \\
94.6\end{array}$ & $\begin{array}{l}29.1 \\
25.4\end{array}$ \\
\hline & $\begin{array}{c}2 \\
2 \mathrm{H}\end{array}$ & $\begin{array}{l}26.33 \\
26.66\end{array}$ & $\begin{array}{l}59,943 \\
59,006\end{array}$ & $\begin{array}{l}.371 \\
.369\end{array}$ & $\begin{array}{l}.193 \\
.191\end{array}$ & $\begin{array}{l}.260 \\
.267\end{array}$ & $\begin{array}{l}.108 \\
.083\end{array}$ & $\begin{array}{l}2.65 \\
2.66\end{array}$ & $\begin{array}{l}6.1 \\
6.2\end{array}$ & $\begin{array}{l}266 \\
259\end{array}$ & $\begin{array}{l}2.55 \\
1.95\end{array}$ & $\begin{array}{l}86.5 \\
88.6\end{array}$ & $\begin{array}{l}33.4 \\
31.0\end{array}$ \\
\hline & $\begin{array}{c}3 \\
3 \mathrm{H}\end{array}$ & $\begin{array}{l}28.57 \\
28.98\end{array}$ & $\begin{array}{l}56,172 \\
56,179\end{array}$ & $\begin{array}{l}.344 \\
.340\end{array}$ & $\begin{array}{l}.197 \\
.197\end{array}$ & \begin{tabular}{|l}
.248 \\
.260
\end{tabular} & $\begin{array}{l}.115 \\
.088\end{array}$ & $\begin{array}{l}2.65 \\
2.67\end{array}$ & $\begin{array}{l}5.5 \\
5.8\end{array}$ & $\begin{array}{l}222 \\
215\end{array}$ & $\begin{array}{l}2.58 \\
1.94\end{array}$ & $\begin{array}{l}81.1 \\
83.7\end{array}$ & $\begin{array}{l}36.0 \\
33.0\end{array}$ \\
\hline & $\begin{array}{c}4 \\
4 \mathrm{H}\end{array}$ & $\begin{array}{l}29.54 \\
29.90\end{array}$ & $\begin{array}{l}59,317 \\
58,689\end{array}$ & $\begin{array}{l}.322 \\
.322\end{array}$ & $\begin{array}{l}.209 \\
.208\end{array}$ & $\begin{array}{l}.248 \\
.263\end{array}$ & $\begin{array}{l}.117 \\
.089\end{array}$ & $\begin{array}{l}2.65 \\
2.67\end{array}$ & $\begin{array}{l}5.5 \\
5.7\end{array}$ & $\begin{array}{l}203 \\
198\end{array}$ & $\begin{array}{l}2.57 \\
1.94\end{array}$ & \begin{tabular}{|l|}
79.5 \\
81.6
\end{tabular} & $\begin{array}{l}36.2 \\
33.3\end{array}$ \\
\hline & 5 & 29.59 & 60,877 & .317 & .214 & .249 & .117 & 2.65 & 5.4 & 203 & 2.57 & 79.5 & 36.3 \\
\hline & $5 \mathrm{H}$ & 30.15 & 818 & 317 & .212 & 257 & .089 & 2.67 & 5.6 & 194 & 1.94 & 80.8 & 33.6 \\
\hline & None & 29.73 & 59,499 & .315 & 21 & .239 & .118 & 2.66 & 5.2 & 200 & 2.58 & 78.5 & 36.9 \\
\hline
\end{tabular}

YC Moves = average number of inter-block linear gantry moves made by all YCs during data collection period (of at least two weeks)

YC Idle $=$ fraction of time that an average YC spends idling (i.e. with no task assigned to it) (averaged over entire simulation run)

YC Gantry $=$ fraction of time that an average YC spends linear gantrying (averaged over entire simulation run)

Cont TravY = time that an avg. container spends traveling towards the yard (i.e. from quay to yard) on a YT prior to being stored in the yard (minutes)

Cont WaitR = time that an avg. container spends waiting for a $\mathrm{YC}$ to retrieve it after a request to retrieve it first appears in the operating system (minutes)

Avg \# YT-Y = time-averaged number of YTs heading towards or waiting at the yard (averaged over the entire simulation run)

Avg \# YT-Q = time-averaged number of YTs heading towards or waiting at the quay (averaged over the entire simulation run) 
Table 9. Effect of vessel berthing policy on performance of penalty regimes: 6-berth terminal in Setting 2 with less equipment.

\begin{tabular}{|c|c|c|c|c|c|c|c|c|c|}
\hline \multirow{2}{*}{$\begin{array}{c}\text { Trial \# } \\
\text { (Objectives } \\
\text { pursued) }\end{array}$} & \multicolumn{3}{|c|}{$\begin{array}{c}\text { HomeBerth Policy } \\
\text { (Copied from Petering, 2015) }\end{array}$} & \multicolumn{3}{|c|}{$\begin{array}{l}\text { FCFS Policy } \\
\text { (Experiment 3) }\end{array}$} & \multicolumn{3}{|c|}{\begin{tabular}{|c} 
Change from HomeBerth to FCFS \\
Positive or (Negative)
\end{tabular}} \\
\hline & GCR & $\begin{array}{c}\text { YT } \\
\text { TravQL }\end{array}$ & $\begin{array}{l}\text { Cont } \\
\text { TravQ }\end{array}$ & GCR & $\begin{array}{c}\text { YT } \\
\text { TravQL }\end{array}$ & $\begin{array}{c}\text { Cont } \\
\text { TravQ }\end{array}$ & GCR & $\begin{array}{c}\text { YT } \\
\text { TravQL }\end{array}$ & $\begin{array}{c}\text { Cont } \\
\text { TravQ }\end{array}$ \\
\hline 0 (none) & 30.62 & .118 & 2.56 & 30.37 & .120 & 2.57 & $(.25)$ & .001 & .01 \\
\hline $\begin{array}{ll}1(\mathrm{~A}) \\
2(\mathrm{~A})\end{array}$ & $\begin{array}{l}28.59 \\
30.37\end{array}$ & $\begin{array}{l}.114 \\
.119\end{array}$ & $\begin{array}{l}2.54 \\
2.58\end{array}$ & $\begin{array}{l}28.66 \\
30.34\end{array}$ & $\begin{array}{l}.116 \\
.120\end{array}$ & $\begin{array}{l}2.54 \\
2.58\end{array}$ & $\begin{array}{l}.07 \\
(.03)\end{array}$ & $\begin{array}{l}.001 \\
.001\end{array}$ & $\begin{array}{l}.00 \\
(.01)\end{array}$ \\
\hline $\begin{array}{ll}3(\mathrm{~B}) \\
4(\mathrm{~B})\end{array}$ & $\begin{array}{l}26.49 \\
28.59\end{array}$ & $\begin{array}{l}.068 \\
.073\end{array}$ & $\begin{array}{l}1.60 \\
1.62\end{array}$ & $\begin{array}{l}25.61 \\
27.65\end{array}$ & $\begin{array}{l}.103 \\
.110\end{array}$ & $\begin{array}{l}2.50 \\
2.50\end{array}$ & $\begin{array}{l}(.88) \\
(.94)\end{array}$ & $\begin{array}{l}.035 \\
.037\end{array}$ & $\begin{array}{l}.90 \\
.88\end{array}$ \\
\hline $5(\mathrm{~A}, \mathrm{~B})$ & 27.77 & .113 & 2.53 & 27.55 & .112 & 2.53 & $(.22)$ & $(.000)$ & .00 \\
\hline $\begin{array}{ll}6 & (\mathrm{C}) \\
7 & (\mathrm{C}) \\
8 & (\mathrm{C}) \\
9 & (\mathrm{C})\end{array}$ & $\begin{array}{l}31.58 \\
31.45 \\
31.53 \\
31.43\end{array}$ & $\begin{array}{l}.119 \\
.119 \\
.119 \\
.119\end{array}$ & $\begin{array}{l}2.57 \\
2.56 \\
2.56 \\
2.56\end{array}$ & $\begin{array}{l}31.53 \\
31.60 \\
31.58 \\
31.72\end{array}$ & $\begin{array}{l}.120 \\
.121 \\
.120 \\
.120\end{array}$ & $\begin{array}{l}2.57 \\
2.57 \\
2.57 \\
2.56\end{array}$ & $\begin{array}{l}.05) \\
.15 \\
.05 \\
.29\end{array}$ & $\begin{array}{l}.001 \\
.002 \\
.001 \\
.001\end{array}$ & $\begin{array}{l}.00 \\
.02 \\
.01 \\
.00\end{array}$ \\
\hline 10 (D) & 31.15 & .119 & 2.56 & 31.16 & .120 & 2.57 & .01 & .001 & .01 \\
\hline
\end{tabular}


Table 10. Effect of vessel berthing policy on performance of yard partitions: 6-berth terminal, Setting 2, less equipment, restrictive YC deployment system, no penalty regime.

\begin{tabular}{|c|c|c|c|c|c|c|c|c|c|}
\hline \multirow[b]{2}{*}{$\begin{array}{c}\text { Yard } \\
\text { Partition }\end{array}$} & \multicolumn{3}{|c|}{$\begin{array}{c}\text { HomeBerth Policy } \\
\text { (Copied from Experiment 2) }\end{array}$} & \multicolumn{3}{|c|}{$\begin{array}{l}\text { FCFS Policy } \\
\text { (Experiment 3) }\end{array}$} & \multicolumn{3}{|c|}{$\begin{array}{c}\text { Change from HomeBerth to FCFS } \\
\text { Positive or (Negative) }\end{array}$} \\
\hline & GCR & $\begin{array}{c}\text { YT } \\
\text { TravQL }\end{array}$ & $\begin{array}{c}\text { Cont } \\
\text { TravQ }\end{array}$ & GCR & $\begin{array}{c}\text { YT } \\
\text { TravQL }\end{array}$ & $\begin{array}{c}\text { Cont } \\
\text { TravQ }\end{array}$ & GCR & $\begin{array}{c}\text { YT } \\
\text { TravQL }\end{array}$ & $\begin{array}{c}\text { Cont } \\
\text { TravQ }\end{array}$ \\
\hline 1 & 10.89 & .044 & 2.51 & 10.89 & .044 & 2.53 & .00 & .000 & .02 \\
\hline $1 \mathrm{H}$ & 10.74 & .032 & 1.87 & 10.93 & .044 & 2.51 & .19 & .012 & .64 \\
\hline $\begin{array}{c}2 \\
2 \mathrm{H}\end{array}$ & $\begin{array}{l}20.33 \\
21.71\end{array}$ & $\begin{array}{l}.084 \\
.067\end{array}$ & $\begin{array}{l}2.57 \\
1.91\end{array}$ & $\begin{array}{l}19.88 \\
21.50\end{array}$ & $\begin{array}{l}.083 \\
.089\end{array}$ & $\begin{array}{l}2.57 \\
2.56\end{array}$ & $\begin{array}{l}(.45) \\
(.21)\end{array}$ & $\begin{array}{c}(.002) \\
.022\end{array}$ & $\begin{array}{c}(.00) \\
.65\end{array}$ \\
\hline $\begin{array}{c}3 \\
3 \mathrm{H}\end{array}$ & $\begin{array}{l}26.25 \\
25.55\end{array}$ & $\begin{array}{l}.108 \\
.078\end{array}$ & $\begin{array}{l}2.57 \\
1.92\end{array}$ & $\begin{array}{l}26.28 \\
24.22\end{array}$ & $\begin{array}{l}.109 \\
.100\end{array}$ & $\begin{array}{l}2.58 \\
2.54\end{array}$ & $\begin{array}{c}.03 \\
(1.32)\end{array}$ & $\begin{array}{l}.001 \\
.021\end{array}$ & $\begin{array}{l}.01 \\
.63\end{array}$ \\
\hline $\begin{array}{c}4 \\
4 \mathrm{H}\end{array}$ & $\begin{array}{l}29.38 \\
27.98\end{array}$ & $\begin{array}{l}.116 \\
.085\end{array}$ & $\begin{array}{l}2.56 \\
1.92\end{array}$ & $\begin{array}{l}29.06 \\
27.33\end{array}$ & $\begin{array}{l}.118 \\
.110\end{array}$ & $\begin{array}{l}2.58 \\
2.53\end{array}$ & $\begin{array}{l}(.31) \\
(.66)\end{array}$ & $\begin{array}{l}.001 \\
.025\end{array}$ & $\begin{array}{l}.02 \\
.61\end{array}$ \\
\hline $\begin{array}{c}5 \\
5 \mathrm{H}\end{array}$ & $\begin{array}{l}30.61 \\
29.26\end{array}$ & $\begin{array}{l}.119 \\
.087 \\
\end{array}$ & $\begin{array}{l}2.56 \\
1.93 \\
\end{array}$ & $\begin{array}{l}30.49 \\
28.59\end{array}$ & $\begin{array}{l}.120 \\
.113 \\
\end{array}$ & $\begin{array}{l}2.57 \\
2.50 \\
\end{array}$ & $\begin{array}{l}(.12) \\
(.66)\end{array}$ & $\begin{array}{l}.001 \\
.025 \\
\end{array}$ & $\begin{array}{r}.01 \\
.58 \\
\end{array}$ \\
\hline None & 30.62 & .118 & 2.56 & 30.41 & .120 & 2.57 & $(.21)$ & .001 & .01 \\
\hline
\end{tabular}


Table 11. Effect of YT traveling speed on performance of penalty regimes: 6-berth terminal in Setting 2 with less equipment.

\begin{tabular}{|c|c|c|c|c|}
\hline \multirow{2}{*}{$\begin{array}{c}\text { Trial \# } \\
\text { (Objectives } \\
\text { pursued) }\end{array}$} & \multicolumn{2}{|c|}{$\begin{array}{c}\text { Truck Speed = Normal } \\
(\text { Copied from Petering, 2015) }\end{array}$} & \multicolumn{2}{|c|}{$\begin{array}{c}\text { Truck Speed }=50 \% \text { Normal } \\
(\text { Experiment } 4)\end{array}$} \\
\hline & GCR & $\begin{array}{c}\text { GCR vs. Trial } 0 \\
\text { Positive or (Negative) }\end{array}$ & GCR & $\begin{array}{c}\text { GCR vs. Trial 0 } \\
\text { Positive or (Negative) }\end{array}$ \\
\hline 0 (none) & 30.62 & - & 23.84 & - \\
\hline $\begin{array}{ll}1 & (\mathrm{~A}) \\
2 & (\mathrm{~A})\end{array}$ & $\begin{array}{l}28.59 \\
30.37\end{array}$ & $\begin{array}{l}(2.03) \\
(.25)\end{array}$ & $\begin{array}{l}23.20 \\
24.01\end{array}$ & $\begin{array}{l}(.63) \\
.17\end{array}$ \\
\hline $\begin{array}{ll}3(\mathrm{~B}) \\
4(\mathrm{~B})\end{array}$ & $\begin{array}{l}26.49 \\
28.59\end{array}$ & $\begin{array}{l}(4.13) \\
(2.03)\end{array}$ & $\begin{array}{l}22.36 \\
23.72\end{array}$ & $\begin{array}{c}(1.48) \\
(.11)\end{array}$ \\
\hline $5(\mathrm{~A}, \mathrm{~B})$ & 27.77 & $(2.85)$ & 23.02 & (.81) \\
\hline $\begin{array}{ll}6 & (\mathrm{C}) \\
7 & (\mathrm{C}) \\
8 & (\mathrm{C}) \\
9 & (\mathrm{C})\end{array}$ & $\begin{array}{l}31.58 \\
31.45 \\
31.53 \\
31.43\end{array}$ & $\begin{array}{l}.96 \\
.83 \\
.91 \\
.81\end{array}$ & $\begin{array}{l}24.56 \\
24.64 \\
24.51 \\
24.61\end{array}$ & $\begin{array}{l}.72 \\
.81 \\
.68 \\
.78\end{array}$ \\
\hline 10 (D) & 31.15 & .53 & 24.14 & .31 \\
\hline
\end{tabular}

